\title{
Deletion of the Gene Encoding the NMDA Receptor GluN1 Subunit in Schwann Cells Causes Ultrastructural Changes in Remak Bundles and Hypersensitivity in Pain Processing
}

\author{
Coralie Brifault, ${ }^{1,2}$ Haylie Romero, ${ }^{1,3}$ Alicia Van-Enoo, ${ }^{1,3}$ Don Pizzo, ${ }^{2}$ Pardis Azmoon, ${ }^{2}$ HyoJun Kwon, ${ }^{1}$ \\ Chanond Nasamran, ${ }^{5}$ Steven L. Gonias, ${ }^{2}$ and Wendy M. Campana ${ }^{1,3,4}$ \\ ${ }^{1}$ Department of Anesthesiology, University of California San Diego, La Jolla, California 92093, ${ }^{2}$ Department of Pathology, University of California \\ San Diego, La Jolla, California 92093, ${ }^{3}$ Program in Neurosciences, University of California, San Diego, La Jolla, California 92093, ${ }^{4}$ San Diego \\ Veterans Administration Health Care System, San Diego, California 92161, and ${ }^{5}$ Center for Computational Biology and Bioinformatics, Department \\ of Medicine, University of California, San Diego, La Jolla, California 92093
}

\begin{abstract}
Abnormalities in interactions between sensory neurons and Schwann cells (SCs) may result in heightened pain processing and chronic pain states. We previously reported that SCs express the NMDA receptor (NMDA-R), which activates cell signaling in response to glutamate and specific protein ligands, such as tissue-type plasminogen activator. Herein, we genetically targeted grin1 encoding the essential GluN1 NMDA-R subunit, conditionally in SCs, to create a novel mouse model in which SCs are NMDA-R-deficient (GluN1- mice). These mice demonstrated increased sensitivity to light touch, pinprick, and thermal hyperalgesia in the absence of injury, without associated changes in motor function. Ultrastructural analysis of adult sciatic nerve in GluN1- mice revealed increases in the density of $\mathrm{A} \delta$ fibers and Remak bundles and a decrease in the density of A $\beta$ fibers, without altered $g$-ratios. Abnormalities in adult Remak bundle ultrastructure were also present including aberrant $\mathrm{C}$-fiber ensheathment, distances between axons, and increased poly-axonal pockets. Developmental and post radial sorting defects contributed to altered nerve fiber densities in adult. Uninjured sciatic nerves in GluN1- mice did not demonstrate an increase in neuroinflammatory infiltrates. Transcriptome profiling of dorsal root ganglia (DRGs) revealed 138 differentially regulated genes in GluN1- mice. One third of the regulated genes are known to be involved in pain processing, including sprr1a, $n p y, f g f 3$, atf 3 , and $c c k b r$, which were significantly increased. The intraepidermal nerve fiber density (IENFD) was significantly decreased in the skin of GluN1- mice. Collectively, these findings demonstrate that SC NMDA-R is essential for normal PNS development and for preventing development of pain states.
\end{abstract}

Key words: neuropathic pain; NMDA-R; non-myelinating Schwann cells; peripheral nerve

Significance Statement

Chronic unremitting pain is a prevalent medical condition; however, the molecular mechanisms that underlie heightened pain processing remain incompletely understood. Emerging data suggest that abnormalities in Schwann cells (SCs) may cause neuropathic pain. We established a novel mouse model for small fiber neuropathy (SFN) in which grin1, the gene that encodes the NMDA receptor (NMDA-R) GluN1 subunit, is deleted in SCs. These mice demonstrate hypersensitivity in pain processing in the absence of nerve injury. Changes in the density of intraepidermal small fibers, the ultrastructure of Remak bundles, and the transcriptome of dorsal root ganglia (DRGs) provide possible explanations for the increase in pain processing. Our results support the hypothesis that abnormalities in communication between sensory nerve fibers and SCs may result in pain states.

Received Mar. 21, 2020; revised Sep. 24, 2020; accepted 0ct. 4, 2020.

Author contributions: W.M.C., C.B., H.R., A.V.-E., and S.L.G. designed research; W.M.C., C.B., H.R., A.V.E., D.P., P.A., H.K., C.N., and S.L.G. performed research; D.P. contributed unpublished reagents/analytic tools; W.M.C., C.B., H.R., A.V.E., D.P., P.A., H.K., C.N., and S.L.G. analyzed data; W.M.C., C.B., H.R., A.V.-E., and S.L.G. wrote the paper.

This work was supported by the National Institutes of Health (NIH) Grant R01 NS097590 (to W.M.C. and S.L.G.), the Veterans Administration Grant 1101RX002484 (to W.M.C.), and the NIH Grant UL1TR001442 to the Clinical and Translational Science Awards. We thank Ying Jones and the Transmission Electron Microscopy Core Facility for help with electron microscopy. We also thank Kristen Jepsen, Kate Fischer, and Annina Schmid for their help with RNA-Seq, bioinformatics analysis, and IENFD methodology, respectively. The authors declare no competing financial interests. Correspondence should be addressed to Wendy M. Campana at wcampana@ucsd.edu. https://doi.org/10.1523/JNEUROSCI.0663-20.2020

Copyright $\odot 2020$ the authors 


\section{Introduction}

In small fiber neuropathy (SFN), damage to or impairment of myelinated A $\delta$ and unmyelinated C-fibers is associated with neuropathic pain, which can be severe and debilitating (Sopacua et al., 2019). Diagnosis of SFN requires skin biopsies to evaluate intraepidermal nerve fiber density (IENFD) and quantitative sensory testing (Devigili et al., 2019). Decreases in IENFD are associated with pain (Devigili et al., 2008; Gasparotti et al., 2017). However, disparities between peripheral nerve pathology and pain severity exist in many neuropathic pain patients (Shillo et al., 2019). In addition, a large portion of SFN cases are idiopathic. Thus, understanding the molecular and cellular mechanisms underlying SFN remains an important goal.

In the PNS, Schwann cells (SCs) provide myelination and ensheathment of axons, which is essential for maintaining axonal integrity (Shy et al., 2002; Harty and Monk, 2017). Myelinating SCs wrap membrane sheaths around large $(\mathrm{A} \beta)$ and medium diameter (A $\delta$ ) axons, whereas non-myelinating SCs ensheath multiple small-diameter C-fibers in the absence of myelin (Jessen and Mirsky, 2005). Clusters of C-fibers in association with a single SC are called Remak bundles; these C-fibers constitute $80 \%$ of the axons in the human peripheral nerve (Griffin and Thompson, 2008). Abnormalities in SCs may be associated with neuropathic pain states, especially following peripheral nerve injury (for review, see Campana, 2007; Harty and Monk, 2017). For example, conditional deletion of the gene encoding LDL receptor-related protein-1 (LRP1) in SCs exacerbates pain-related behaviors in mice after partial sciatic nerve ligation (Orita et al., 2013). Deletion of the GABA-B receptor in myelinating SCs causes hyperalgesia and tactile allodynia even in the absence of nerve injury (Faroni et al., 2014).

In addition to its primary role in mediating excitatory synaptic transmission in neurons (Chen and Kukley, 2020), the NMDA receptor (NMDA-R) has been identified in myelinating and non-myelinating SCs (Kinkelin et al., 2000; Christensen et al., 2016). We demonstrated that SCs in primary culture express multiple NMDA-R subunits, including GluN1, GluN2b, GluN2c, and GluN3b (Campana et al., 2017). In response to glutamate, SCs demonstrate robust cell signaling, including activation of ERK1/2 and Akt (Campana et al., 2017). SCs also require the NMDA-R to respond to protein ligands that activate cell signaling, such as tissue-type plasminogen activator, activated $\alpha_{2}$-macroglobulin, and matrix metalloprotease-9 (Mantuano et al., 2015). Understanding how SC NMDA-R regulates PNS physiology is an important objective.

In this study, we deleted the gene encoding the essential GluN1 NMDA-R subunit, grin1, conditionally in SCs, by expressing Cre recombinase under the control of the myelin protein zero (P0) promoter (Feltri et al., 2002). In the resulting SC GluN1-deficient (GluN1-) mice, myelination of sciatic nerves was unchanged; however, the density of $\mathrm{A} \delta$ fibers and C-fibers in Remak bundles was increased while the density of $\mathrm{A} \beta$ fibers was decreased. In adult GluN1- mice, major ultrastructural abnormalities in Remak bundles were observed, including an increase in the incidence of polyaxonal pockets, large variations in the distance between $\mathrm{C}$ fibers, and irregular ensheathment of C-fibers. The increase in abundance of Remak bundles and the abnormalities observed in adult nerves were partially explained by ultrastructural analysis of sciatic nerves during development. GluN1- mice demonstrated increased mechanical and thermal sensitivity and reduced IENFD. These signs are reminiscent of those observed in SFN and fibromyalgia (Oaklander, 2016). grin1 deletion in SCs significantly modified the transcriptome profile of dorsal root ganglia (DRGs), which house sensory neuron cell bodies. A large cohort of the regulated genes are associated with pain processing. These results identify SC NMDA-R as a major regulator not only of SC function but also, pain states. The GluN1- mouse model offers the potential to contribute to our understanding of SFN and fibromyalgia.

\section{Materials and Methods}

\section{Animals}

Transgenic mice that are homozygous for floxed grin1 $\left(\operatorname{grin} 1^{\mathrm{f} / \mathrm{fl}}\right.$;

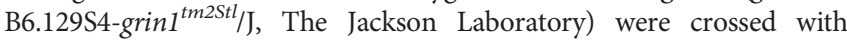
$\mathrm{P} 0-\mathrm{Cre}$ mice (strain B6N.FVB-Tg(Mpz-cre)26Mes/J) that express Cre recombinase under the control of the $\mathrm{P} 0$ promoter in the $\mathrm{C} 57 \mathrm{BL} / 6 \mathrm{~J}$ background (Feltri et al., 1999, 2002). In this strain of P0-Cre mice, Cre is embedded in the complete endogenous mouse $\mathrm{P} 0$ regulatory domain and thus, there is a high level of specificity for SCs (Feltri et al., 1999, 2002). Age matched male littermates that were $\operatorname{grin}^{\text {flox/flox }}$ and either $\mathrm{P} 0$-Cre-negative (GluN1+) or P0-Cre-positive (GluN1-) were compared. All animal experiments were approved by the Institutional Animal Care and Use Committee at University of California San Diego.

\section{Primary mouse SC cultures}

Primary cultures of mouse SCs were isolated as previously described (Wang et al., 2013) with minor modifications. Adult mice were deeply anesthetized with isoflurane and euthanized by cervical dislocation. Sciatic nerve fragments $(1.5 \mathrm{~cm})$ were surgically resected, rinsed, placed in complete medium consisting of DMEM, $10 \%$ fetal bovine serum (FBS; Invitrogen), $2 \mu \mathrm{M}$ forskolin, and $10 \mathrm{ng} / \mathrm{ml}$ neuregulin- $\beta-1$ (R\&D Systems; catalog $\# 9875-\mathrm{NR}$ ) and incubated at $37^{\circ} \mathrm{C}$ in a $\mathrm{CO}_{2}$ incubator for a week. The medium was changed once every two days. At $7 \mathrm{~d}$, nerve fragments were digested with a mixture of collagenase $(0.2 \%$, Stemcell Technologies) and $0.2 \%$ Dispase (Stemcell Technologies) at $37^{\circ} \mathrm{C}$. After centrifugation, cell pellets were re-suspended in complete medium. Cells were plated in poly-L-lysine-coated T25-flasks $(10 \mu \mathrm{g} / \mathrm{ml}$, SigmaAldrich) at a density of $5 \times 105$ cells/flask.

\section{RNA isolation and RT-qPCR}

Adult GluN1 + and GluN1- mice were euthanized and uninjured sciatic nerves and DRGs were harvested. Sciatic nerves were stripped of epineurium. Nerves from two equivalent mice were pooled to generate one replicate ( $n=4$ /experiment). Total RNA was extracted in Trizol and purified using the Nucleospin RNA kit (Macherey-Nagel). The same kit was used to purify total RNA from cultured SCs. RNA was reverse-transcribed using the iScript cDNA synthesis kit (Bio-Rad). RT-qPCR was performed using TaqMan gene expression products and an AB Step one Plus Real-Time PCR System (Applied Biosystems). The relative change in gene expression was calculated using the $2^{\Delta \Delta \mathrm{Ct}}$ method. GAPDH mRNA was measured as a standard. The primer-probe sets used included: gapdh (Mm99999915_g1), grin1 (Mm00433790_m1), grin2b (Mm00433820_m1), lrp1 (Mm00464608-m1), sox10 (Mm00569909_m1), sprrla (Mm01962902_s1), npy (Mm01410146_m1), and atf3 (Mm00476033_m1), thfa (Mm00443258_m1) and ccl2 (Mm00441242_m1).

\section{Immunoblot analysis}

Proteins from sciatic nerves and DRGs were extracted in RIPA buffer (20 mm sodium phosphate, $150 \mathrm{~mm} \mathrm{NaCl}, \mathrm{pH} \mathrm{7.4,1 \%}$ Triton X-100, $0.5 \%$ sodium deoxycholate, and $0.1 \%$ SDS) supplemented with Complete Protease Inhibitor Cocktail and phosphatase inhibitor (Roche Diagnostics). Equal amounts of cellular protein were loaded onto Protean TGX gels (Bio-Rad) and electro-transferred to PVDF membranes (Bio-Rad). The membranes were blocked with 5\% nonfat dry milk in $10 \mathrm{~mm}$ Tris- $\mathrm{HCl}, 150 \mathrm{~mm} \mathrm{NaCl}, \mathrm{pH} 7.4$, and $0.1 \%$ Tween 20 (TBS-T buffer) and incubated with the following primary antibodies: 
anti-GluN1 (1:1000; Cell Signaling Technology, catalog \#5704S) and anti-GAPDH (1:5000; SIGMA, catalog \#G9545). Primary antibodies were detected with HRP-conjugated species-specific secondary antibodies (Cell Signaling Technology). Conjugated antibodies were detected with the ECL reagent, Prosignal (Prometheus), and the Azure C300 imaging system. Densitometry analysis was performed using ImageJ software.

\section{Immunohistochemistry (IHC) and image analysis}

Animals were deeply anesthetized with isoflurane and subjected to intracardiac perfusion with fresh PBS followed by $4 \%$ paraformaldehyde. For IHC, sciatic nerve tissues were paraffin embedded. Cross sections $(4 \mu \mathrm{m})$ were prepared (at least three from each harvested tissue) and stained with antibodies for myelin P0 (Abcam, catalog \#ab183868), GFAP (Dako, catalog \#Z0334), CD11b (Abcam, catalog \#ab133357), and Sox10 (Cell Marque, catalog \#ab383A). Nerve sections on slides were stained using a Ventana Discovery Ultra (Ventana Medical Systems). Antigen retrieval was performed using $\mathrm{CC} 1$ (Tris based; $\mathrm{pH}$ 8.5) for $40 \mathrm{~min}$ at $95^{\circ} \mathrm{C}$. Slides were incubated with the primary antibody for $30 \mathrm{~min}$ at $37^{\circ} \mathrm{C}$. The secondary antibody (HRP-coupled goat anti-rabbit; OmniMap system; Ventana, catalog \#760-4311) was incubated on the sections for $12 \mathrm{~min}$ at $37^{\circ} \mathrm{C}$ and visualized using diaminobenzidine as a chromogen followed by hematoxylin as a counterstain. Slides were rinsed, dehydrated through alcohol and xylene and cover slipped. Light microscopy was performed using a Leica DFC420 microscope with Leica Imaging Software 2.8.1 (Leica Biosystems).

Immunofluorescence (IF) microscopy was performed to examine cultured mouse SCs fixed in 4\% PFA. Slides were incubated with primary antibody directed against $\mathrm{p} 75^{\mathrm{NTR}}$ (rabbit monoclonal 1:1000, Cell Signaling, catalog \#8238) for $16 \mathrm{~h}$ at $4^{\circ}$. Species-specific secondary antibody was applied (Alexa Fluor 488-conjugated donkey anti-rabbit IgG; Invitrogen, catalog \#A21207). Sections were mounted and viewed using an inverted fluorescent microscope (DMi8; Leica Biosystem). Control nerve sections were treated with secondary antibody only. At least three sections from each tissue were analyzed.

\section{Assessment of motor and sensory function}

Mice were acclimated to the behavior testing facility for at least $30 \mathrm{~min}$. For experiments using von Frey hairs and insect pins, animals were placed on a mesh stand. For thermal testing, animals were placed on a Plexiglas platform with a radiant heat source. For all sensory and motor testing, each animal was tested on three independent days. Results were averaged and subjected to statistical analysis. All experiments were performed by an investigator blinded to mouse identity.

\section{von Frey test}

Mechanical sensitivity was tested by applying $0.04-$ to 4 -g von Frey filaments (Stoelting) to the plantar surface of the ipsilateral hind paw. Filaments were presented in a consecutive fashion, either ascending or descending, using the up-down method as previously described (Dixon, 1980; Chaplan et al., 1994) and modified for mouse (Poplawski et al., 2018). The filament that caused paw withdrawal $50 \%$ of the time [the $50 \%$ paw withdrawal threshold (PWT)] was determined.

\section{Pinprick test}

Response to mechanical stimuli was tested by gently applying an Austerlitz insect pin (size 000; FST) to the plantar surface of the hind paw as previously described (Poplawski et al., 2018). The pin was applied to two areas, the most lateral toe and the mid-lateral area of the paw, with at least a 5-min interval. A response was considered positive when the animal briskly removed its paw, and the test was graded 1 for this area. If the application did not elicit a positive response, the grade was 0 . The saphenous territory (medial paw) of the same paw was tested as a positive control, which always elicited a positive response. Each area was tested twice and the results of the two tests were averaged.

\section{Hargreaves test}

Responses to thermal stimuli were tested on both hind paws as previously described (Hargreaves et al., 1988; Poplawski et al., 2018) using the Basile plantar test apparatus (Ugo Basile). A constant intensity radiant heat source (30 I.R.) was aimed at the midplantar area of the hind paw with a cutoff at $10 \mathrm{~s}$ to avoid any possible burning injury. The time from heat source activation until paw withdrawal was automatically recorded. Each paw was tested three times with 10-min intervals and the results of the three tests were averaged.

\section{Rotarod}

Motor function testing was performed using an accelerating Rotarod (Ugo Basile). The Rotarod speed was increased from four to 40 rotations per minute over a 300-s time period. The latency to fall (sec) reflects the average of three different trials each day.

\section{Transmission electron microscopy}

Sciatic nerves from adult, postnatal day (P)5 and P15 GluN1- and littermate control GluN1 + mice were processed for plastic embedding. Adult mice were deeply anesthetized with isoflurane and subjected to intracardiac perfusion with fresh $20 \mathrm{~mm}$ sodium phosphate, $150 \mathrm{~mm} \mathrm{NaCl}, \mathrm{pH}$ 7.4 (PBS) followed by glutaraldehyde (2.5\%) in PBS. Nerve tissue ( $5 \mathrm{~mm}$ ) was then collected $15 \mathrm{~mm}$ distal from the DRG. P5 mice were euthanized and nerve tissue $(2 \mathrm{~mm})$ was collected $2 \mathrm{~mm}$ distal from the DRG. P15 mice were euthanized and nerve tissue $(5 \mathrm{~mm})$ was collected 3-5 mm distal from the DRG. Collected nerves were immersed in modified Karnovsky's fixative ( $2 \%$ glutaraldehyde in $0.10 \mathrm{~m}$ sodium cacodylate buffer), and further postfixed in $1 \% \mathrm{OsO}_{4}$ in $0.1 \mathrm{M}$ cacodylate buffer for $1 \mathrm{~h}$. Tissues were stained with $2 \%$ uranyl acetate for $1 \mathrm{~h}$, dehydrated in serially increasing series of ethanol (50-100\%) while remaining on ice. Tissues were then subjected to one wash with $100 \%$ ethanol and two washes with acetone, then embedded in Durcupan epoxy resin. Sections were cut at $60 \mathrm{~nm}$ on a Leica UCT ultramicrotome, and picked up on 300 mesh copper grids. Sections were poststained with $2 \%$ uranyl acetate for $5 \mathrm{~min}$ and Sato's lead stain for $1 \mathrm{~min}$. Grids were viewed using a JEOL 1200EX II (JEOL) transmission electron microscope and photographed using a Gatan digital camera (Gatan).

\section{Quantitative analyses of TEM images}

In transverse semithin sections of P5 sciatic nerve, myelinated nerve fibers, not-myelinated sorted axons, unsorted axon bundles, and total sorted axons were counted (10-13 thin sections per sciatic nerve; $n=3$ mice/cohort). In P15 mice, myelinated nerve fibers and not-myelinated axon bundles (early Remak bundles) were counted (nine thin sections per mouse; $n=3$ mice/cohort). In adult mice, myelinated axons, Remak bundles, and total axons in Remak bundles were counted (8-13 thin sections per sciatic nerve; $n=3$ mice/cohort) Thus, the total number of sections imaged per mouse genotype was 25-27 (adult) and 32-37 (P5, $\mathrm{P} 15)$. Sections that were imaged at $1500 \times$ were used to quantify myelinated fibers, including $\mathrm{A} \beta, \mathrm{A} \delta$ fibers, and Remak bundles in adult sciatic nerves and to quantify myelinated and not-myelinated sorted axons in P5 nerves. The density of specific fiber types was determined in randomly selected fields using ImageJ software and is reported based on a $625 \mu^{2}$ area (mean \pm SEM). High-magnification images $(4000 \times)$ were used to determine the mean diameter of $\mathrm{A} \delta$ fibers and Remak axons, to calculate $g$-ratios, and to identify and quantify abnormalities in Remak bundle structure. Remak bundle abnormalities that were assessed in adult sciatic nerves included: (1) the presence of SC cytoplasm invaginations; (2) the absence of SC cytoplasm between C-fibers in Remak bundle, defined as poly-axonal pockets; and (3) the lack of SC cytoplasm separating C-fibers from endoneurium at the periphery of the Remak bundle. The area of over 300 randomly selected Remak bundle-associated axons was determined using ImageJ. Each area was converted into a corresponding diameter, assuming the axon was a perfect circle, according to the equation: $\mathrm{A}=\pi\left(\frac{1}{2} \mathrm{D}\right)^{2}$.

\section{Transcriptome profiling}

Total RNA was extracted from three GluN1+ and three GluN1- DRGs collected at the L3-L4 level as described above and analyzed separately to generate a total of six transcriptome profiles. RNA was assessed for quality using an Agilent Tapestation 4200. RNA sequencing libraries were generated from samples with an RNA integrity number (RIN) $>8.0$, using the TruSeq Stranded mRNA Sample Prep Kit with TruSeq Unique Dual Indexes (Illumina). Profiling was conducted with an Illumina 
HiSeq 4000. Samples were demultiplexed using bcl2fastq v2.20 Conversion Software (Illumina). Quality control of the raw fastq files was performed with the software tool, FastQC v0.11.8 (Wingett and Andrews, 2020). Sequencing reads were trimmed with Trimmomatic v0.38 (Bolger et al., 2014) and aligned to the mouse genome (GRCm38) using the STAR aligner v2.6.0a (Dobin et al., 2013). Read quantification was performed with RSEM v1.3.0 (Li and Dewey, 2011) and the Ensembl release 68 annotation. The R BioConductor packages edgeR (Robinson et al., 2010) and limma (Ritchie et al., 2015) were used to implement the limma-voom method for differential expression analysis (Law et al., 2014). In brief, minimally expressed genes (those without counts per million $\geq 1$ in at least three of the samples) were filtered out. Then, trimmed mean of $M$ values (TMM) normalization was applied (Robinson and Oshlack, 2010). The experimental design was modeled on condition $(\sim 0+$ condition). The voom method was employed to model the mean-variance relationship in the log-cpm values weighted for intersubject correlations in repeated measures of subjects after which $\operatorname{lmFit}$ was used to fit per-gene linear models and empirical Bayes moderation was applied with the eBayes function. Significance was defined by an adjusted $p$ value cutoff of $0.05(n=3)$ after multiple testing correction (Benjamini and Hochberg, 1995) using a moderated $t$ statistic in limma. Functional enrichment of the differentially expressed genes was determined using GSEA (Subramanian et al., 2005), WebGestalt (Zhang et al., 2005), and SPIA (Tarca et al., 2009). The pathway figures were generated using $\log \mathrm{FC}$ values in Pathview (Luo and Brouwer, 2013).

\section{IENFD analysis}

IENFD was assessed in the hind paw footpad. After euthanasia, the plantar glabrous skin was collected, fixed in $4 \% \mathrm{PFA}$, and stored at $4^{\circ} \mathrm{C}$ in sucrose. Floating frozen sections $(16 \mu \mathrm{m})$ were immuno-stained with rabbit anti-PGP-9.5 (1:200; Zytomed) as described by Schmid et al. (2014). Primary antibody was detected using Alexa Fluor 488-conjugated donkey anti-rabbit IgG (A21207; Invitrogen). Control sections were treated with secondary antibody only. DAPI (blue) identified nuclei. Sections were mounted and viewed using a confocal laser scanning microscope (LSM 880 with Airyscan; Zeiss). IENFD was quantified in PGP9.5 stained sections by a blinded investigator according to guidelines of Lauria et al. (2010) and expressed as profiles per mm epidermis.

\section{Experimental design and statistical analysis}

Statistical analysis was performed using GraphPad Prism 5.0 (GraphPad Software Inc.). All results are expressed as the mean \pm SEM. The normality of data was confirmed using the Kolmogorov-Smirnov test. Comparisons between two groups were performed using two-tailed unpaired, paired or nested $t$ tests. When we compared greater than two groups, one-way ANOVA was performed. Body weight measurements and measurements of inflammatory pain, in which we collected multiple
B

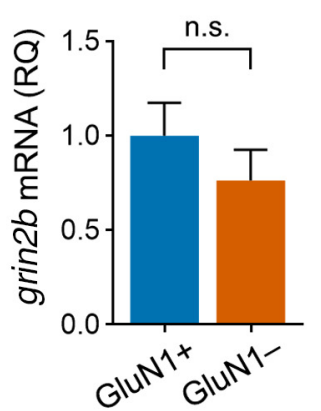

C

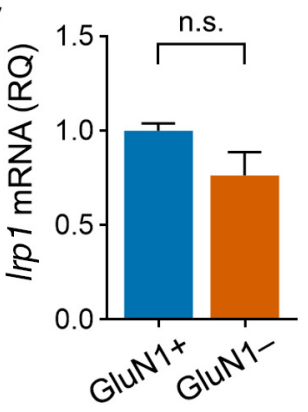

$\mathbf{E}$
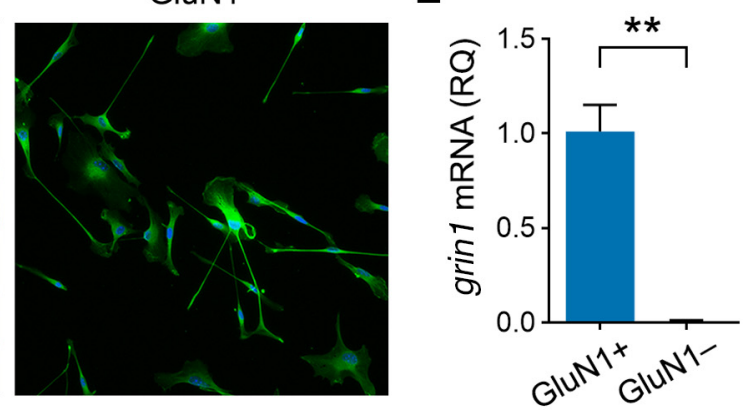

H

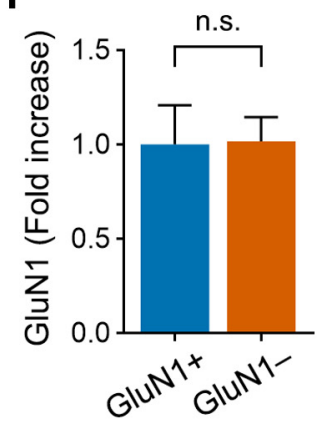

Figure 1. Specific deletion of grin1 in SCS. A-C, Sciatic nerves were harvested from GluN1+ and GluN1- mice and RT-qPCR experiments were performed to quantify expression level of $(\boldsymbol{A})$ grin $1 \mathrm{mRNA}$ comparing GluN1+ $(n=3)$ and $\operatorname{GluN1} 1-(n=3)$ nerves. Data are expressed as the mean \pm SEM $\left(t_{(7)}=4.165 * * p=0.004\right.$, unpaired two-tailed $t$ test); $(B)$ grin2 $b$ mRNA comparing GluN1 $+(n=7)$ and GluN1- $(n=6)$ nerves. Data are expressed as mean \pm SEM $\left(t_{(11)}=0.9850\right.$, n.s. $p=0.346$; unpaired two $t$ test); ( $(C)$ Irp 1 mRNA comparing GluN1 $+(n=3)$ and GluN1- $(n=3)$ nerves. Data are expressed as the mean \pm SEM $\left(t_{(4)}\right.$ $=1.859$, n.s. $p=0.1365$; unpaired two-tailed $t$ test). $\boldsymbol{D}$, Primary cultures of mouse SCs were established and immunostained to detect the SCs marker p7 $5^{\text {NTR }}$ (green). Representative IF microscopy images are presented for GluN1+ (left) and GluN1- (right) cells. Nuclei are counterstained with DAPI. Scale bar: $50 \mu \mathrm{m}$. $\boldsymbol{E}$, Total RNA was extracted from primary cultures of SCs, isolated from GluN1 $+(n=5$ independent cultures) and GluN1- ( $n=3$ independent cultures) mice. grin 1 mRNA expression was measured by RT-qPCR. Data are expressed as the mean \pm SEM $\left(t_{(6)}=5.285, * * p=0.002\right.$; two-tailed unpaired $t$ test $)$. $\boldsymbol{F}-\boldsymbol{H}$, DRGs were collected from GluN1 $+(n=3)$ and GluN1- $(n=3)$ mice. $F$, RT-qPCR was performed to quantify expression of grin1 mRNA in DRG extracts. Data are expressed as mean \pm SEM (n.s. $p=0.7$, Mann-Whitney two-tailed test). G, Immunoblot analysis was performed to detect the GluN1 subunit of the NMDA-R. GAPDH serves as a loading control. $\boldsymbol{H}$, Densitometry analysis was performed to determine the relative level of GluN1 protein standardized against the loading control. Data are expressed as a GluN1/GAPDH ratio from GluN1 $+(n=6)$ and GluN1- $(n=5)$ DRGs. Data are mean \pm SEM $\left(t_{(9)}=1.069\right.$, n.s. $p=0.3128$; unpaired two-tailed $t$ test).

observations in individual mice over time, were analyzed by repeated measures ANOVA. Statistical analyses (exact $p$ values, degrees of freedom, effect sizes) for each experiment are reported in the corresponding figure legends; $p<0.05$ was considered statistically significant.

\section{Results}

Targeted disruption of grin 1 in SCs

Mice in which grin 1 is flanked by loxP sites were crossed with mice in which Cre recombinase is expressed under the control of the P0 promoter (Feltri et al., 1999; Orita et al., 2013) to generate 

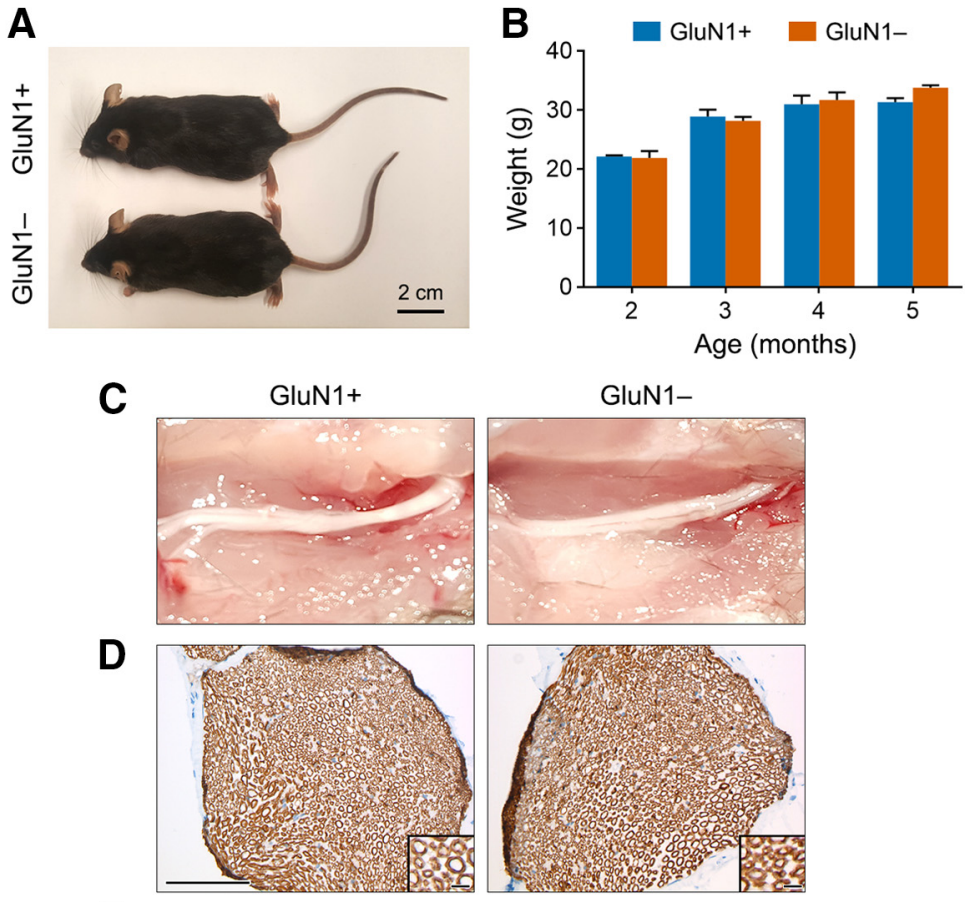

$\mathrm{E}$
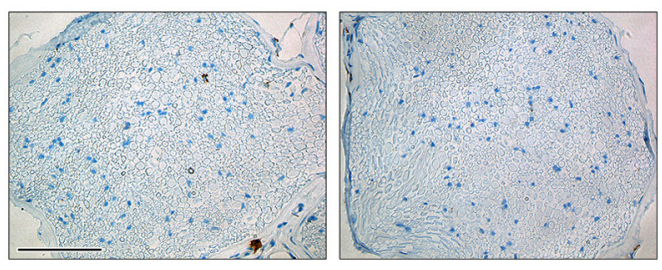

$\mathbf{F}$

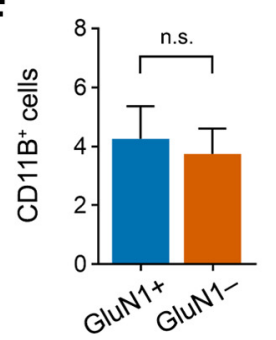

G

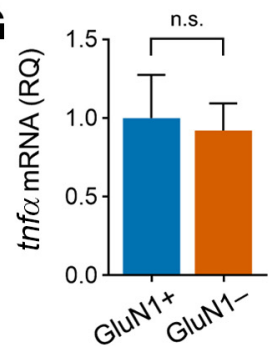

H

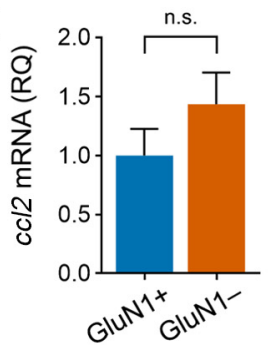

Figure 2. Effect of grin1 deletion in SCS on mouse physiology and sciatic nerve structure. $A$, Representative images of GluN1+ (top) and GluN1- (bottom) mice. B, Histogram showing GluN1+ $(n=6)$ and GluN1- $(n=6)$ mouse weight at two, three, four, and five months of age. No statistical difference was found at each time point. Data shown are the mean $\pm \operatorname{SEM}\left(F_{(3,40)}=1.066\right.$, n.s. $p=0.3747$; repeated measures ANOVA). C, Representative images of sciatic nerves from threemonth-old GluN1+ and GluN1- mice. $\boldsymbol{D}, \boldsymbol{E}$, Representative IHC images of transverse nerve sections for (D) P0 and $(\boldsymbol{E})$ Cd11b. Scale bar: $100 \mu \mathrm{m} . \boldsymbol{F}, \mathrm{CD} 11 \mathrm{~b}+$ cells were quantitated in GluN1+ $(n=5)$ and GluN1- $(n=4)$ nerves. Data shown are the mean \pm SEM $\left(t_{(6)}=0.3573\right.$, n.s. $p=0.7331$; two-tailed unpaired $t$ test). $G$, RT-qPCR was performed to quantify expression of tnf $\alpha$ mRNA in GluN1+ $(n=3)$ and GluN1- $(n=3)$ nerves. Data are mean \pm SEM $\left(t_{(4)}=0.2395\right.$, n.s. $p=0.8225$; two-tailed unpaired $t$ test). $\boldsymbol{H}$, ccl2 mRNA was determined in GluN1+ $(n=4)$ and GluN1- $(n=4)$ nerves. Data shown are the mean $\pm \operatorname{SEM}\left(t_{(6)}=1.236\right.$, n.s. $p=0.2625$; two-tailed unpaired $t$ test $)$.

GluN1- mice. The P0 promoter becomes active specifically in SC precursors at embryonic day 13.5-14.5, including cells that develop into myelinating and non-myelinating SCs. GluN1+ mice carry two copies of floxed grin 1 but are P0-Cre negative. To examine the efficiency of grin 1 gene deletion, first, sciatic nerves were harvested and RNA was isolated. SCs are responsible for $>80 \%$ of the RNA in uninjured sciatic nerves (Asbury, 1970). grin $1 \mathrm{mRNA}$ was decreased by $69.0 \pm 0.2 \%$ in sciatic nerves isolated from GluN1- mice compared with GluN1 + littermate controls $(p<0.01$; Fig. $1 A)$. Intact NMDA-R cannot assemble in the absence of GluN1 (Lee et al., 2014). grin2b mRNA expression was similar in sciatic nerves from GluN1+ and GluN1- mice
(Fig. $1 B$ ), as was $\operatorname{lrp} 1$ mRNA (Fig. 1C), which is important because the NMDA$\mathrm{R}$ and LRP1 function as co-receptors in mediating cell signaling in response to protein ligands (Mantuano et al., 2015).

Next, we isolated SCs from sciatic nerves of adult GluN1+ and GluN1mice and established primary cultures. IF microscopy was performed to examine p $75^{\text {NTR }}$, a biomarker of the non-myelinated and "repair" SC phenotypes. As shown in Figure $1 D$, SCs isolated from both GluN1+ and GluN1- mice were similar in appearance and immunopositive for $\mathrm{p} 75^{\mathrm{NTR}}$. RT-qPCR demonstrated a $99 \%$ decrease in the mRNA encoding GluN1 in cultured SCs from GluN1mice compared with GluN1+ mice $(p<0.01$; Fig. $1 E)$.

The $\mathrm{P} 0$ promoter used in our studies is reported to be inactive in CNS glia and in DRG neurons (Feltri et al., 1999, 2002). As a control, L3-L4 DRGs were collected from GluN1+ and GluN1- mice. grin1 mRNA was quantified by RT-qPCR. Similar levels of grin1 mRNA were detected in DRGs from GluN1+ and GluN1- mice (Fig. $1 F$ ). Similar levels of GluN1 protein also were detected, as shown in the representative immunoblot analysis (Fig. $1 G$ ) and by densitometry of five to six separate immunoblots (Fig. $1 H$ ). Although these experiments are limited by the diversity of cell types in the DRG, our results support previous studies (Feltri et al., 1999, 2002), indicating that the $\mathrm{P} 0$ promoter specifically drives gene deletion in SCs in the PNS.

\section{GluN1 - mice do not demonstrate gross abnormalities}

GluN1- mice were grossly normal. These mice were fertile and born at the expected Mendelian frequency. Adult GluN1mice were the same size and weight as GluN1+ mice (Fig. 2A,B). Gait and motor function were qualitatively intact and there was no evidence of neurologic abnormalities.

Sciatic nerves in GluN1- mice appeared normal in size and structure (Fig. $2 C$ ). Abnormalities in myelination, which may manifest as a translucent appearance to the sciatic nerve, were not visible using a magnifying glass. No differences were observed when crosssections of sciatic nerves from GluN1+ and GluN1- mice were compared by IHC for P0 (Fig. 2D). P0 immunostaining confirmed the presence of intact myelinated axons in nerves from both genotypes.

To determine whether the number of resident and bloodderived macrophages changed in uninjured sciatic nerves from GluN1- mice, we performed IHC for CD11b. In addition to macrophages, CD11b-specific antibody immunostains monocytes, 
neutrophils, and NK cells (Wong et al., 2011). The density of CD11b-positive cells was unchanged in GluN1- mice (Fig. 2E,F). To further confirm that there is no ongoing inflammation in uninjured sciatic nerves in GluN1mice, we quantified expression of the mRNAs encoding the pro-inflammatory cytokine, $\operatorname{tnf} \alpha$, and the chemokine, ccl2, in sciatic nerve extracts. Expression of $\operatorname{tnf} \alpha$ and $c c l 2$ was unchanged (Fig. 2G,H). These results indicate that GluN1 deficiency in SCs is not associated with gross abnormalities in sciatic nerve structure or inflammatory infiltrates.

\section{SC populations are altered in}

GluN1- mice

To determine whether NMDA-R deficiency regulates SC abundance, sciatic nerves from GluN1+ and GluN1mice were immunostained to detect Sox10 (Fig. 3A). Sox10 is a transcription factor necessary for SC development, which persists in the nuclei of myelinating and non-myelinating adult SCs (Kuhlbrodt et al., 1998). Morphometric analysis of the Sox 10 IHC images demonstrated that the density of Sox10-positive nuclei was increased in GluN1- nerves $(p<0.05$; Fig. $3 B$ ), suggesting an increase in the density of SCs. We also quantified sox10 mRNA expression by RT-qPCR and demonstrated that sox 10 mRNA is increased in GluN1- nerves $(p<0.05$; Fig. $3 C$ ). This result would argue that Sox10 expression may be regulated in individual SCs from GluN1- mice since most of the RNA harvested from peripheral nerves is SC derived.

Next, we measured GFAP, a biomarker of non-myelinating SCs in uninjured nerves (Jessen and Mirsky, 1984). GFAP immunoreactivity was apparent in nerves from both GluN1and GluN1+ mice (Fig. 3D). A trend toward increased GFAP immunoreactivity was observed in GluN1- nerves $(p=0.063$; Fig. $3 E)$. This result may be explained as a trend toward more non-myelinating SCs in GluN1- sciatic nerves or a change in the area occupied by each SC.

\section{grin1 deletion regulates proportions of myelinated nerve} fibers but does not affect $\boldsymbol{g}$-ratios

Next, we compared sciatic nerves from adult GluN1- and GluN1+ mice by TEM. Representative images showing A $\beta$ fibers, A $\delta$ fibers and Remak bundles are shown in Figure $4 A$. The density of large diameter myelinated $\mathrm{A} \beta$ fibers $(>6 \mu \mathrm{m})$ was decreased in sciatic nerves from GluN1- mice $(6.2 \pm 0.4)$ compared with GluN1+ littermate controls $(7.9 \pm 0.2 ; p<0.01$;
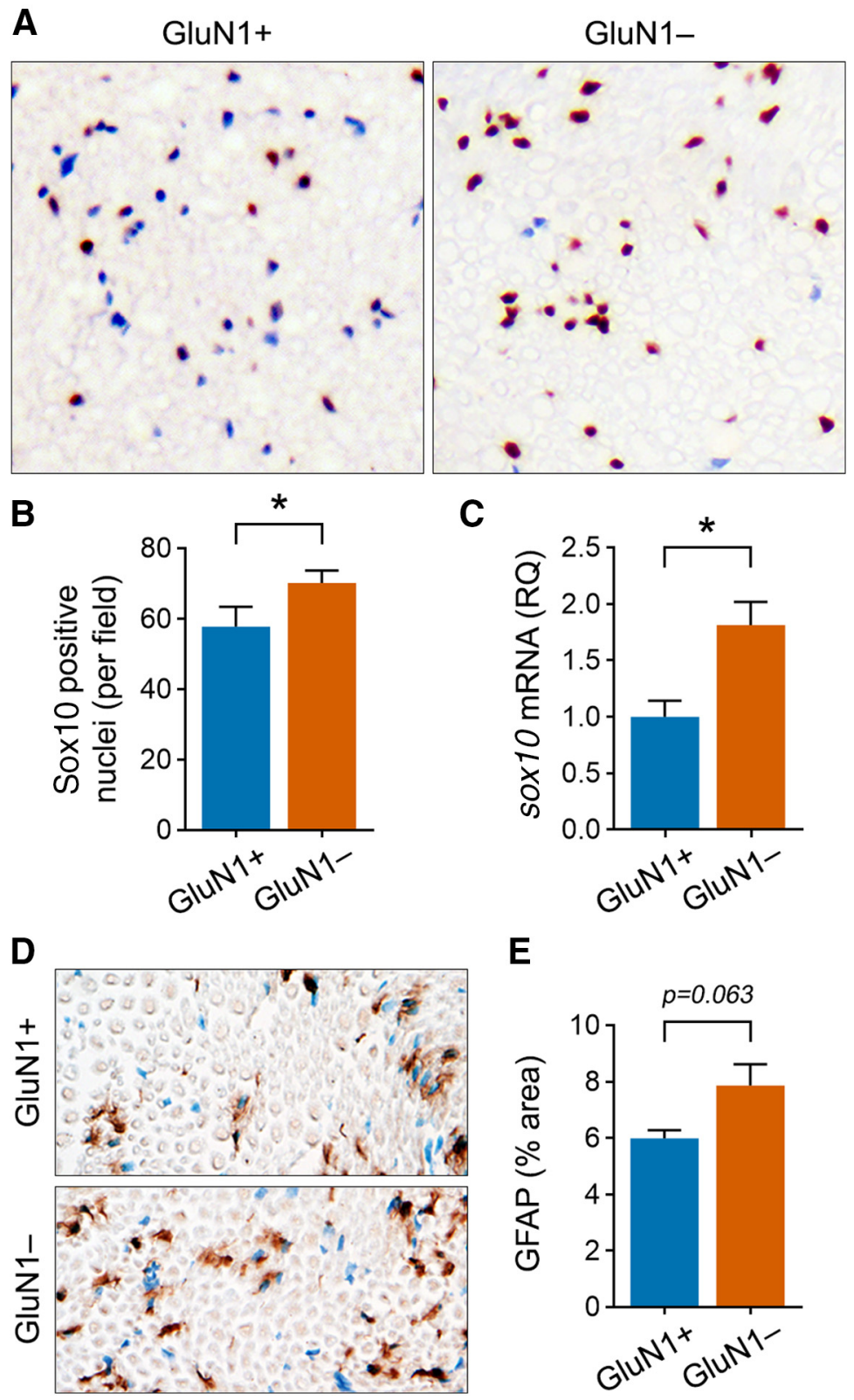

E

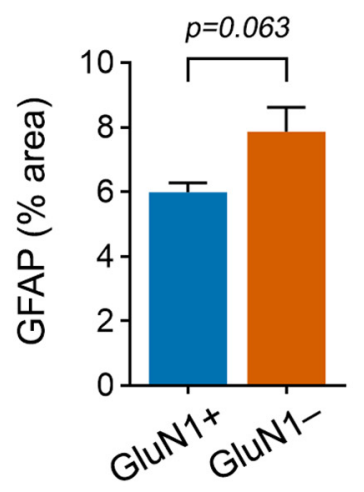

Figure 3. Sox10 immunoreactivity and mRNA are increased in GluN1- mouse sciatic nerves. $\boldsymbol{A}$, Representative images of Sox10 immunoreactive cells in transverse sections of sciatic nerves from GluN1+ and GluN1- mice; $400 \times$. B, Quantification of Sox 10 immunopositive nuclei per whole transverse nerve section $(100 \times)$ from GluN1 $+(n=8)$ and GluN1- $(n=8)$ mice. Data are expressed as the mean \pm SEM $\left(t_{(7)}=2.621, * p=0.0343\right.$; two-tailed paired $t$ test). $C$, RT-qPCR experiments were performed $\left(t_{(7)}=3.034 * p=0.019\right.$; two-tailed unpaired $t$ test). $\boldsymbol{D}$, Representative images of GFAP immunoreactivity in transverse sections of sciatic nerves from GluN1+ and GluN1- mice. $\boldsymbol{E}$, Quantification of GFAP in GluN1+ $(n=4)$ and GluN1- $(n=4)$ sciatic nerve. Data are mean \pm SEM $\left(t_{(6)}=2.282\right.$ n.s. $p=0.063$; two-tailed unpaired $t$ test).

Fig. $4 B)$. By contrast, the density of $\mathrm{A} \delta$ fibers was increased in GluN1- mice $(19.7 \pm 1.1$ vs $11.0 \pm 0.6 ; p<0.0001$; Fig. $4 C)$. The increase in density of $\mathrm{A} \delta$ fibers in GluN1- mice was not accompanied by a change in the mean diameter of $\mathrm{A} \delta$ fibers (Fig. 4D).

Representative images of small myelinated $\mathrm{A} \delta$ fibers are shown in Figure 4E. To confirm that grin1 deletion in SCs did not affect myelination, myelinated axons (90-95 fibers) with diameters ranging from 3 to $10 \mu \mathrm{m}$ were selected randomly from images of sciatic nerves from three separate GluN1- and GluN1 + mice; $g$-ratios, which report the mean axonal diameter divided by the mean fiber diameter, were calculated. As shown 
A
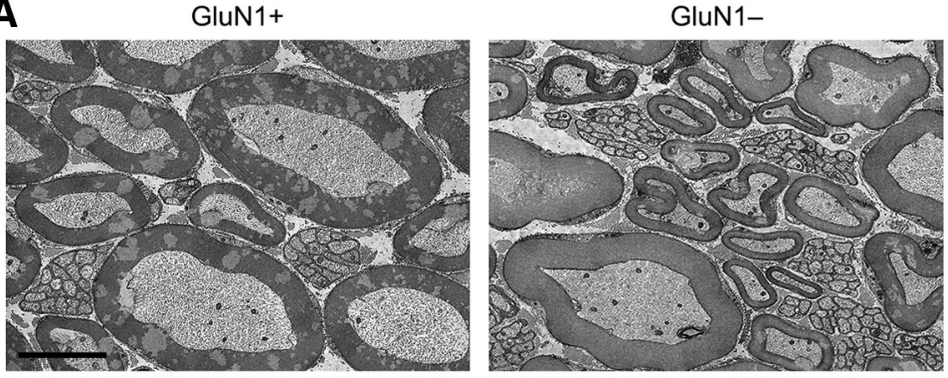

B

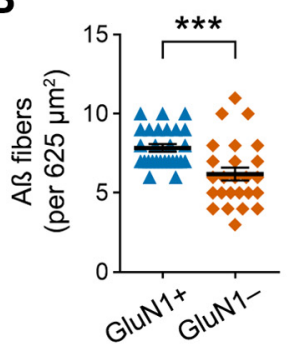

C
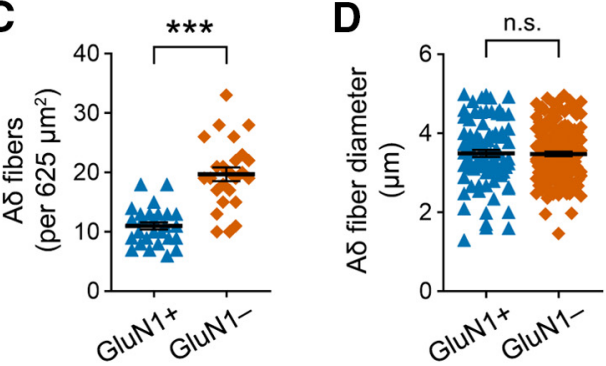

$\mathbf{E}$
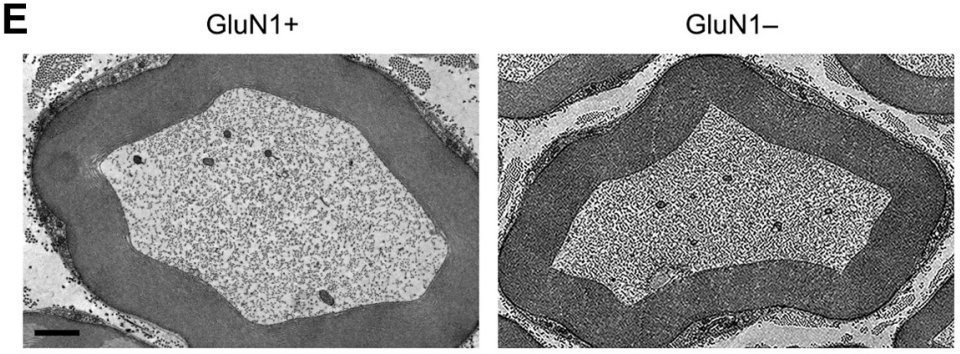

$\mathbf{F}$

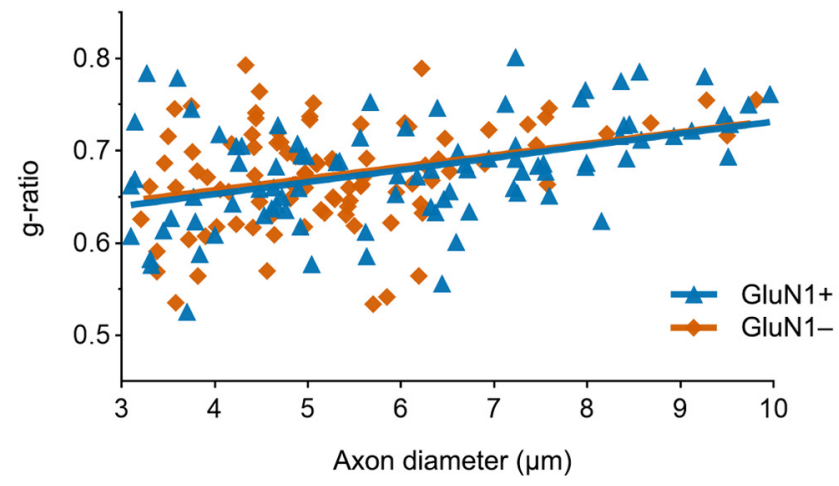

Figure 4. Ultrastructural analysis of sciatic nerves in GluN1- mice. $\boldsymbol{A}$, Representative TEM images showing myelinated $\mathrm{A} \beta, A \delta$, and non-myelinated C-fibers in sciatic nerves from GluN1+ (left) and GluN1- (right) mice (1500 $\times$; scale bar: $5 \mu \mathrm{m})$. $\boldsymbol{B}$, Quantification of large diameter, $A \beta$ axons per field $\left(625 \mu \mathrm{m}^{2}\right)$ in GluN1 $+(n=27)$ and GluN1- $(n=25)$ sciatic nerves. The data shown are the mean \pm SEM $\left(t_{(50)}=3.564 * * p=0.0008\right.$, two-tailed unpaired $t$ test). $C$, Quantification of A $\delta$ fibers per field $\left(625 \mu \mathrm{m}^{2}\right)$ in sciatic nerves from GluN1+ $(n=27)$ and GluN1- $(n=25)$ mice. Data are the mean \pm SEM $\left(t_{(50)}=6.833 * * * p<0.0001\right.$, two-tailed unpaired $t$ test). $\boldsymbol{D}$, Measure of the diameter of $A \delta$ fibers in sciatic nerves from GluN1+ $(n=86)$ and GluN1- $(n=147)$ mice. $A \delta$ fibers are $<5 \mu \mathrm{m}$ in diameter. The data shown are the mean \pm SEM $\left(t_{(230)}=1.395\right.$ n.s. $p=0.8892$, two-tailed unpaired $t$ test). $\boldsymbol{E}$, Representative TEM images of A $\delta$ axons $(2000 \times$; scale bar: $1 \mu \mathrm{m}) . \boldsymbol{F}$, Scatter plots showing $g$-ratios versus axon diameter for myelinated axons from GluN1+ $(n=90)$ and GluN1$(n=95)$ mice. Simple linear regression revealed $F_{(1,181)}=0.011$ n.s. $p=0.9176$. No difference in the slopes for the $g$-ratios was observed. All images are of four-month-old mice.

in Figure $4 F$, the $g$-ratios distributed similarly when nerves from GluN1 - and GluN1 + mice were compared.

\section{grin1 deletion in SCs alters Remak bundle abundance and ultrastructure}

Given the limited sensitivity of GFAP immunoreactivity in determining the density of non-myelinating SCs, we analyzed TEMs at high magnification $(4000 \times)$ to more accurately study the abundance and structure of Remak bundles in sciatic nerves from GluN1- and GluN1+ mice. Image analysis of electron micrographs confirmed that the density of Remak bundles was significantly increased in GluN1- sciatic nerves $(10.6 \pm 0.9$ vs $4.2 \pm 0.4$; $p<0.0001$; Fig. 5A). This corresponded with an increased number of Remak bundle-associated axons in GluN1- mice $(p<0.0001$; Fig. 5B). The number of axons per Remak bundle in GluN1mouse nerves distributed into a pattern that was not obviously changed compared with GluN1+ mice (Fig. 5C) and consistent with the distribution anticipated in wild-type mice (Murinson and Griffin, 2004).

High-magnification ultrastructural analysis of Remak bundles showed that in GluN1 + mice, the axons were uniformly ensheathed by extensions of SC cytoplasm so that the outer axonal membranes of each axon were approximately equidistant from each other throughout the Remak bundle (Fig. 5D, top panels). By contrast, the axons in Remak bundles in GluN1mice demonstrated highly irregular ensheathment by SC cytoplasm (Fig. 5D, bottom panels). The abnormalities observed included invagination of SC cytoplasm (Fig. 5D, bottom left panel), poly-axonal pockets (Fig. 5D, asterisks), and direct exposure of the axon to the endoneurium because of locally absent or thinned SC ensheathment (Fig. 5D, arrowheads).

Quantitative image analysis revealed a greater than twofold increase in the percentage of Remak bundle-associated axons impacted by apparent abnormalities in ultrastructure in GluN1- mice, compared with GluN1 + mice $(p<0.001$; Fig. $5 E$ ). Poly-axonal pockets are rare in Remak bundles in wild-type peripheral nerves (Murinson and Griffin, 2004); however, in sciatic nerves from GluN1mice, the number of Remak bundles containing one or more poly-axonal pocket doubled $(p<0.05$; Fig. $5 F)$. The frequency of exposure of C-fibers to the endonerium increased more than fourfold in GluN1- mice $(p<0.0001$; Fig. $5 G)$. These results demonstrate that grin1 deletion in SCs affects Remak bundle ultrastructure.

When abnormalities in the PNS involve principally Remak bundles, this may be attributed to a late axonal sorting defect or a postsorting defect in differentiation of nonmyelinating SCs (Feltri et al., 2016). Late axonal sorting defects are characterized by an increase in large axons $(>1.0 \mu \mathrm{m})$ within Remak bundles. We therefore measured 
A

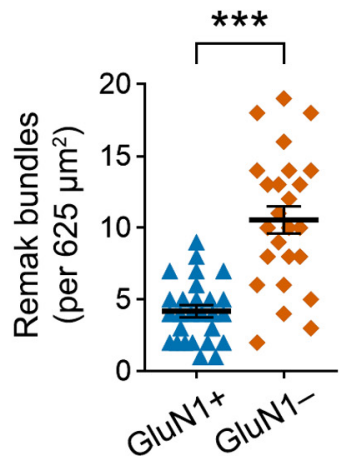

B

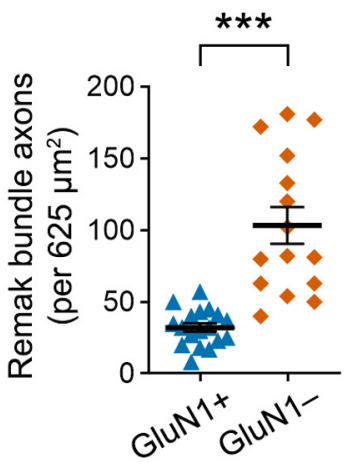

C

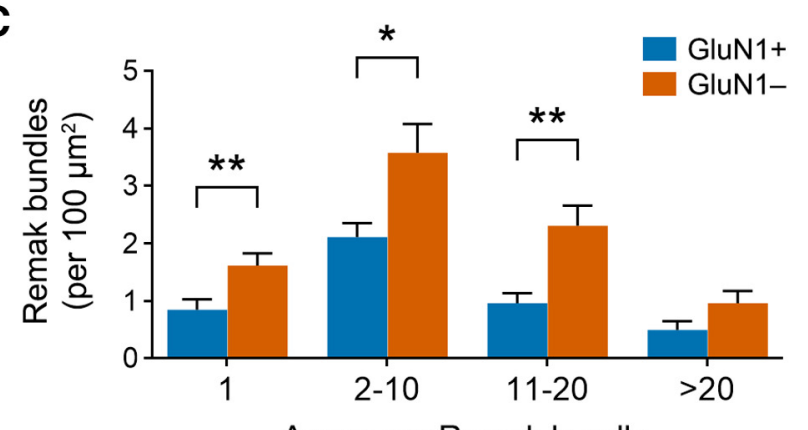

Axons per Remak bundle
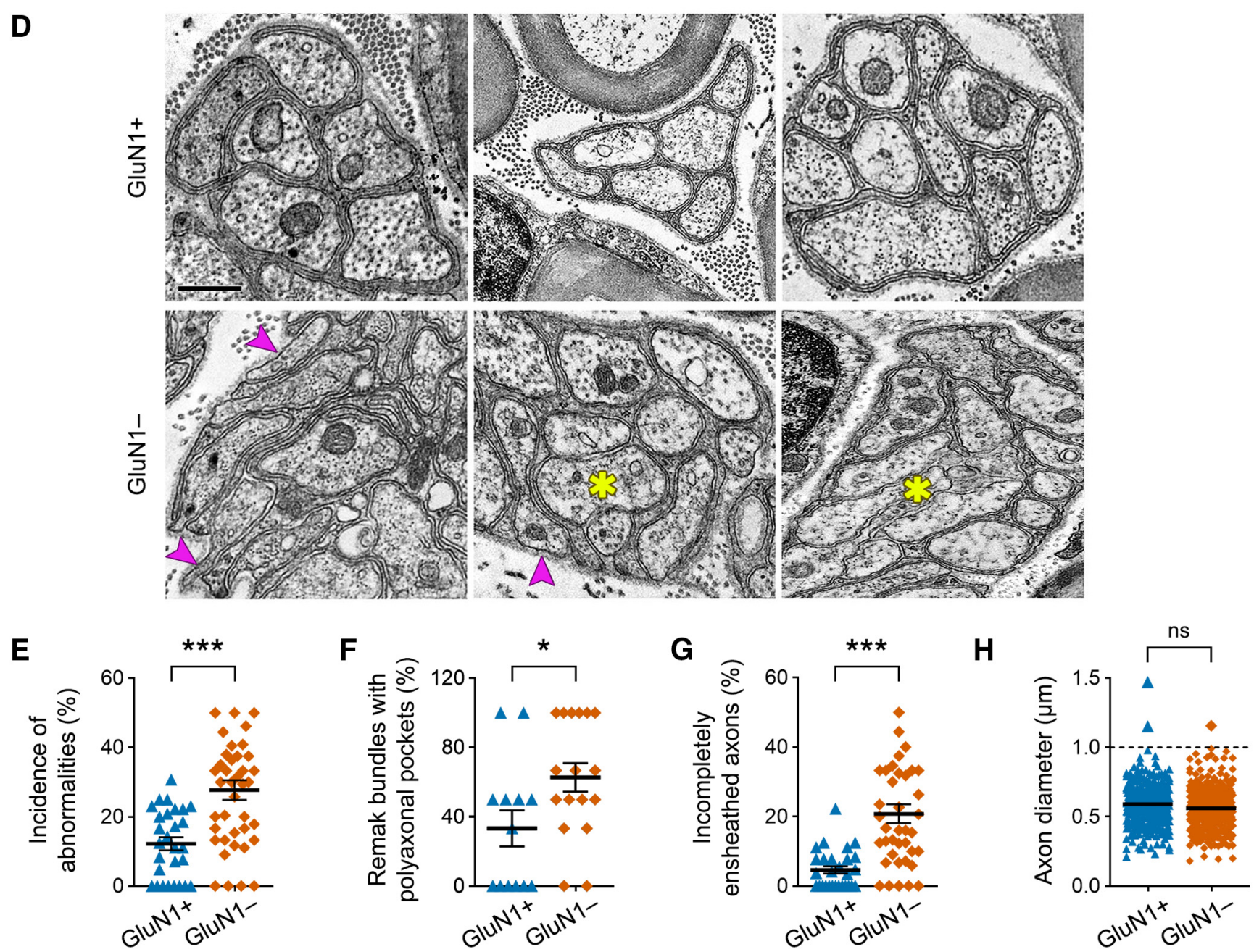

Figure 5. grin1 deletion in SCs alters Remak bundles. $A$, Quantification of Remak bundle density (per $\left.625 \mu \mathrm{m}^{2}\right)$ in transverse nerve sections from GluN1+ $(n=27)$ and GluN1- $(n=25)$ mice (four-month-old). Data are mean \pm SEM $\left(t_{(50)}=6.34 p<0.0001\right.$; two-tailed unpaired $t$ test). $\boldsymbol{B}$, Total number of Remak axons in transverse nerve sections $\left(625 \mu \mathrm{m}^{2}\right)$ from GluN1+ and GluN1- mice, $t_{(31)}=5.931, * * * p<0.001$. C, Analysis of Remak bundles showing the number of $(-$ fibers ensheathed within each Remak bundle in GluN1+ $(n=26)$ and GluN1$(n=26)$ nerve sections (one axon, $t_{(50)}=2.732, * * p=0.0087 ; 2-10$ axons, $t_{(50)}=2.602, * p=0.0121 ; 11-20$ axons, $t_{(50)}=3.423, * * p=0.0012 ;$ and $>20$ axons, $t_{(50)}=1.785$, $p=0.0803$ ). The data shown are the mean \pm SEM for each group analyzed by a two-tailed unpaired $t$ test. (D) Representative images of Remak bundles in GluN1+ (top panel) and GluN1(bottom panel) sciatic nerves ( $4000 \times$; scale bar: $500 \mathrm{nm).} \mathrm{E-H,} \mathrm{Quantification} \mathrm{of} \mathrm{abnormalities} \mathrm{in} \mathrm{Remak} \mathrm{bundles.} \mathrm{Abnormalities} \mathrm{are} \mathrm{defined} \mathrm{as} \mathrm{(1)} \mathrm{SCs} \mathrm{cytoplasm} \mathrm{invagination} \mathrm{(bottom} \mathrm{left}$ image); (2) poly-axonal pockets (asterisk); and (3) axons in direct contact with the endonerium (arrowhead). $\boldsymbol{E}$, Abnormal Remak bundles were counted and expressed as a percentage of total number of Remak bundles in GluN1+ $(n=30)$ an GluN1- $(n=30)$ nerves. The data shown are the mean \pm SEM $\left(t_{(66)}=4.134 * * * p<0.0001\right.$, two-tailed unpaired $t$ test $)$. $\boldsymbol{F}$, The number of Remak bundles containing one or more poly-axonal pockets in GluN1+ $(n=13)$ and GluN1- $(n=17)$ nerves was determined and expressed as a percentage of the total number of Remak bundles. The data shown are the mean \pm SEM $\left(t_{(28)}=4.134 * p=0.0326\right.$, two-tailed unpaired $t$ test). $G$, Axons in direct contact with the endonerium that were not ensheathed correctly by SCs cytoplasm were counted and expressed as a percentage of total axons per Remak bundle in GluN1+ $(n=28)$ and GluN1- $(n=39)$ nerves. The data shown are the mean \pm SEM $\left(t_{(65)}=\right.$ $4.899 * * * p<0.0001$, two-tailed unpaired $t$ test). $\boldsymbol{H}$, Remak axon diameter sizes in GluN1+ and GluN1- mice did not reveal large axons $>1 \mu \mathrm{m} ;(n=6)$. The data shown are the mean \pm SEM; $t_{(4)}=0.8472$, n.S, two-tailed nested $t$ test. 
A
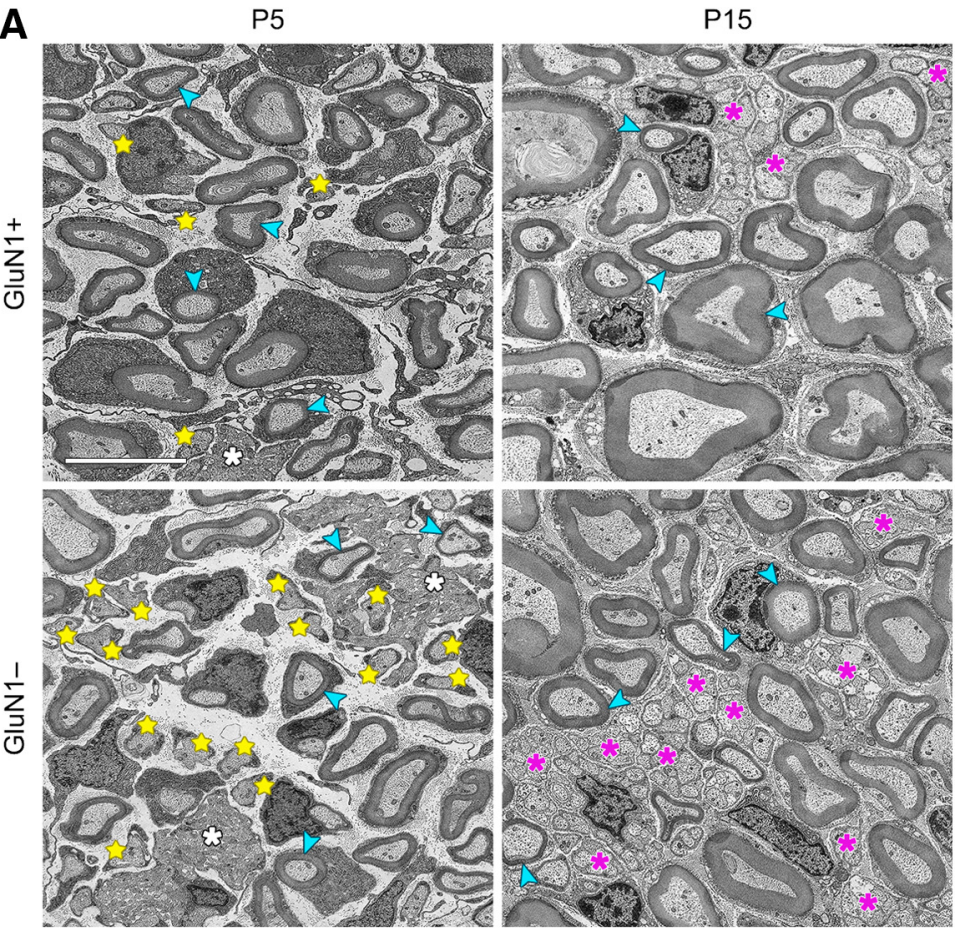

B

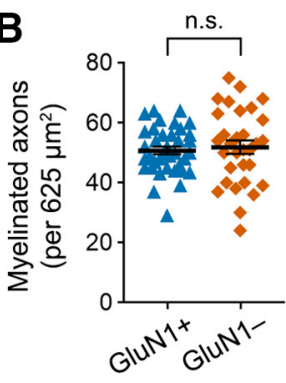

C

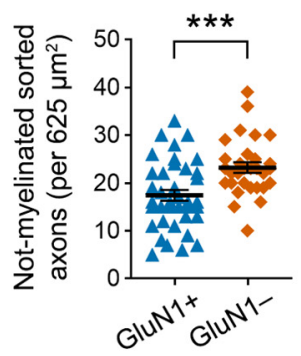

D

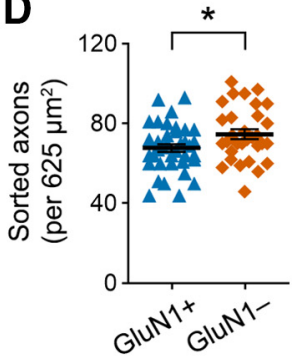

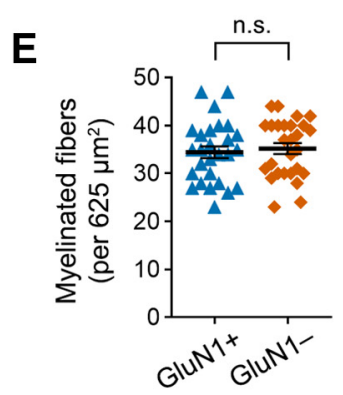

$\mathbf{F}$

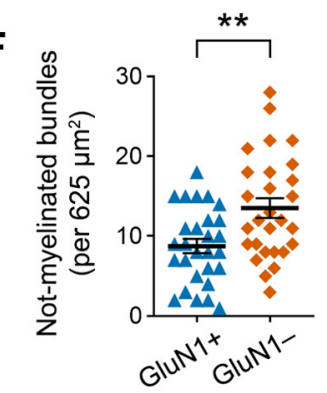

Figure 6. Absence of GluN1- in SCS manifests defects in development during radial sorting. $\boldsymbol{A}$, Electron micrographs of $\mathrm{P5}$ and P15 sciatic nerves from GluN1 + and GluN1- mice. In P5, bundles of unsorted axons are indicated by white asterisks. Blue arrows point to examples of myelinated axons and yellow stars identify sorted but not myelinated axons. In P15, bundles of not-myelinated axons are indicated by purple asterisks. Blue arrows point to examples of myelinated axons. Scale bar: $5 \mu \mathrm{m}$. $\boldsymbol{B}-\boldsymbol{D}$, Quantification of morphologic features of P5 sciatic nerves. The number of myelinated axons, $t_{(66)}=0.4387$, n.s. $(\boldsymbol{B})$, the number of not-myelinated sorted axons, $t_{(66)}=3.599$, ***p $<0.001(\boldsymbol{C})$, and the number of total sorted axons, $t_{(66)}=2.247$, $* p<0.05(\boldsymbol{D})$ were determined per cross section $\left(625 \mu^{2}\right)$. All results are the mean \pm SEM and analyzed by two-tailed unpaired $t$ test. $\boldsymbol{E}, \boldsymbol{F}$, Quantification of TEM in P15 nerves. $\boldsymbol{E}$, The number of myelinated axons, $t_{(52)}=0.4633$, n.s. were determined per cross section $\left(625 \mu \mathrm{m}^{2}\right)$. $\boldsymbol{F}$, The number of not-myelinated bundles, $t_{(54)}=3.182, * * p<0.01$. All results are the mean \pm SEM and analyzed by two-tailed unpaired $t$ test.

over 300 randomly selected Remak bundle-associated axons in electron micrographs of nerves from GluN1- and GluN1+ mice. The mean axonal diameter was slightly decreased in nerves from GluN1- mice. However, most importantly, the fraction of large axons was not increased in GluN1- Remak bundles (Fig. 5H).

\section{Loss of GluN1 in SCs alters early radial sorting of axons}

To identify abnormalities in development of GluN1- mice that may explain the ultrastructural changes observed in adult sciatic nerves, we analyzed P5 and P15 sciatic nerves by TEM. In both GluN1- and GluN1+ mice, P5 sciatic nerve included unsorted bundles of axons, myelinated axons, and not-myelinated sorted axons (Fig. 6A). Image analysis revealed that the density of myelinated axons was unchanged in GluN1- mice, compared with GluN1+ mice (Fig. 6B); however, the density of not-myelinated sorted axons was significantly increased in GluN1- mice $(p<0.05$; Fig. $6 C)$, and contributed to an increase in the overall density of sorted axons (Fig. 6D). At P15, once again that the density of myelinated fibers was not altered in GluN1- mice (Fig. 6E); however, the density of axon bundles, partially or fully ensheathed by a single non-myelinating SC (early Remak bundles) almost doubled in the GluN1- mouse ( $p<0.01$; Fig. $6 F)$.

\section{GluN1 - mice demonstrate mechanical and thermal hypersensitivity}

GluN1+ and GluN1- mice were compared in experiments examining mechanical and thermal sensitivity in the absence of sciatic nerve injury. First, mechanical sensitivity was measured by non-noxious probing of the hindpaw using von Frey filaments. In GluN1mice, 50\% PWTs were significantly lower compared with GluN1+ mice $(p<0.05$; Fig. $7 A)$, a result that indicates tactile hypersensitivity. Next, the response of GluN1+ and GluN1- mice to sharp stimuli was compared using the pinprick test, which consists of gently applying an insect pin to the lateral toe and the most lateral part of the hind paw. Again, GluN1- mice demonstrated a statistically significant increase in response $(p<0.05$; Fig. $7 B)$, suggesting increased mechanical sensitivity. In thermal hyperalgesia experiments, using the Hargreaves apparatus, the latency for paw withdrawal from a focal radiant heat source was significantly decreased in GluN1- mice $(p<0.05$; Fig. $7 C)$, indicating thermal hyperalgesia in these animals. By contrast, no change in motor function was evident when GluN1+ and GluN1- mice were compared using the Rotarod test (Fig. 7D).

To test response to inflammatory pain, mice were subjected to formalin injections in the hind paw. As anticipated, formalin 
A

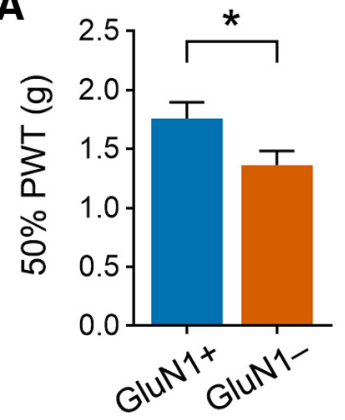

C

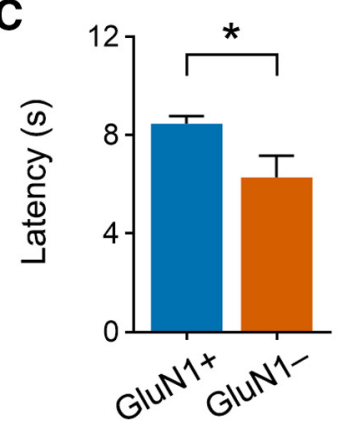

E

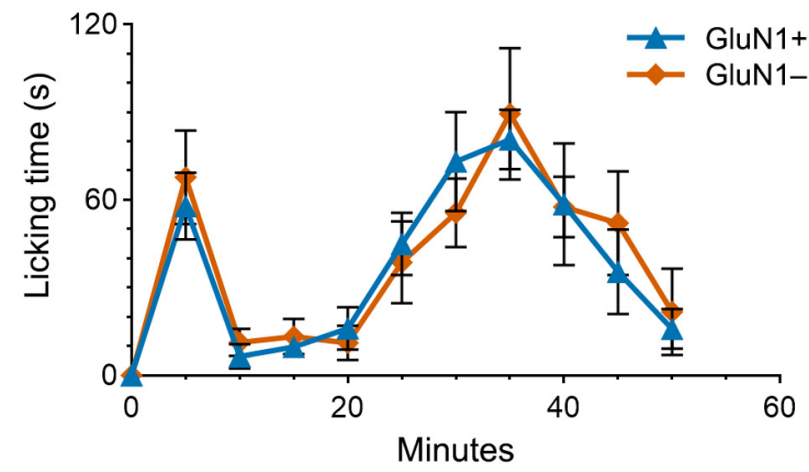

B

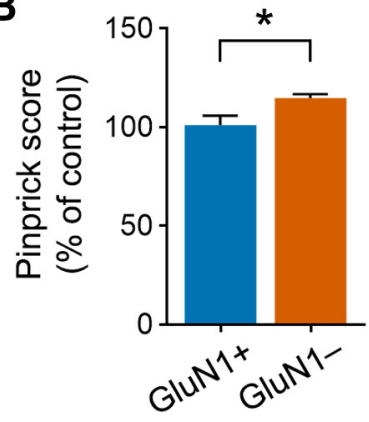

D

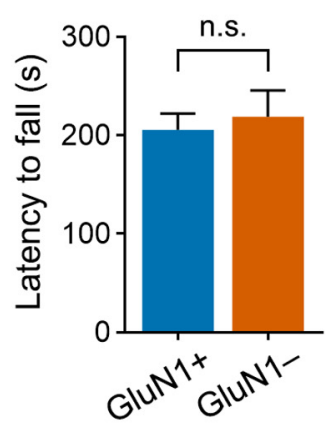

Figure 7. GluN1- mice demonstrate altered thermal and mechanical nociception. $\boldsymbol{A}, \boldsymbol{B}$, Mechanical sensitivity was measured by nnocuous and noxious probing of the hind paw using $(\boldsymbol{A})$ von Frey filaments in gram weight $(\mathrm{g})$ and $(\boldsymbol{B})$ pin prick, respectively, in GluN1+ $(n=12)$ and GluN1- $(n=12)$ mice. The data shown are the mean \pm SEM $\left[t_{(22)}=2.195\right.$ $* p=0.0390$, two-tailed unpaired $t$ test (von Frey) and $t_{(22)}=2.577 * p=0.0219$, two-tailed unpaired $t$ test (pinprick)]. C, Thermal sensitivity was measured using the Hargreaves apparatus. The paw withdrawal latency was measured in seconds using an infrared intensity of 30 in GluN1 $+(n=8)$ and GluN1- $(n=8)$ mice. The data shown are the mean \pm SEM $\left(t_{(14)}=\right.$ $2.324 * p=0.0357$, two-tailed unpaired $t$ test). $\boldsymbol{D}$, Motor function was assessed using an accelerated Rotarod (4-40 rpm over a 500-s period) in GluN1+ $(n=12)$ and GluN1$(n=12)$ mice. The data shown are the mean \pm SEM $\left(t_{(22)}=0.6120\right.$ n.s. $p=0.5468$, twotailed unpaired $t$ test). $\boldsymbol{E}$, Formalin testing in GluN1 $+(n=7)$ and GluN1- $(n=8)$ mice was performed to assess the response to inflammatory pain. The time course of paw-licking following a subcutaneous injection of $20 \mu \mathrm{l}$ of formalin (5\% in saline) in the hind paw is shown (left diagram). Each point represents the average amount of time a mouse spent licking the injected paw during a 5-min period. The data shown are the mean $\pm \operatorname{SEM}\left(F_{(10,154)}=0.011\right.$ n.s. $p=0.9755$, repeated measures ANOVA). Age matched mice, three to five months, in both genotypes were compared.

induced vigorous licking of the paw in two distinct periods (Hunskaar et al., 1985); an "early" phase 1 response within the first $5 \mathrm{~min}$ followed by a "later stage" second phase lasting from 20 to $50 \mathrm{~min}$ (Fig. 7E). Analysis of the individual phases, by cumulative time spent licking during the early and the late phase, revealed no statistically significant differences between GluN1+ and GluN1- mice (Fig. 7E), demonstrating that grin1 deletion in SCs does not regulate inflammatory pain.

\section{Transcriptome profiling of DRGs}

We compared the DRG transcriptomes of uninjured adult GluN1- and GluN1+ mice. A total of 138 differentially regulated genes were identified, as shown in the heat map and volcano plot (Fig. $8 A, B$ ). The data have been submitted to GEO, a public database (accession number is GSE154182). The largest share of regulated genes was in the category, "biological regulation" (Fig. $8 C)$. A large fraction of the regulated genes was localized to the plasma membrane (Fig. $8 D$ ). KEGG pathway analysis (entry mmu04080) revealed key regulated genes that control neuronal function, including GABA and opioid receptors, which were downregulated, and the cholecystokinin 2 receptor, $c c k b r$, the G-coupled receptor, Gpr151, and the serotonin transporter, SLC6A4, which were upregulated (Fig. 8B,E).

Overall, greater than one-third of all differentially regulated genes were associated with pain pathways and are activated in persistent or chronic pain. Heat map analysis of the 50 most significant pain-related genes are shown in Figure 9A. ATF3, NPY, and sprrla were validated by RT-qPCR and were increased by 14-fold, 45-fold, and 160-fold, respectively, in DRGs from GluN1- mice $(* p<0.05, * * p \leq 0.01$; Fig. $9 B-D)$. ATF3 and NPY are upregulated in previously described injury-induced neuropathic pain models. In GluN1- mice, regulation of expression of ATF3 and NPY occurs in the absence of nerve injury. The 15 most significantly regulated pain genes, together with the fold-change in expression ( $\left.2^{\mathrm{a}} \log \mathrm{FC}\right)$, adjusted $p$ values, and references to pain processing are listed in Table 1.

\section{Deletion of grin 1 in SCs alters peripheral nerve terminals}

Because decreased IENFD is characteristic of SFN and observed in other painful syndromes such as fibromyalgia (Clauw, 2015), we performed IF to detect PGP9.5 (green) in skin biopsies of GluN1- and GluN1+ mice. PGP9.5 is a pan-axonal marker and identifies small nerve fibers in cutaneous skin (Schmid et al., 2014). The density of PGP9.5-positive nerve profiles in skin was significantly decreased in GluN1- mice, compared with GluN1+ mice ( $p<0.05$; Fig. 10).

\section{Discussion}

In the United States, the prevalence of chronic pain ranges from $11 \%$ to $40 \%$ in adults (Dahlhamer et al., 2018). Identifying molecular mechanisms that underlie chronic pain remains an important scientific objective. Recent studies in mouse model systems have identified dysfunctional SCs as a cause of neuropathic pain (Orita et al., 2013; Faroni et al., 2014). Herein, we demonstrated that conditional grin1 deletion in SCs causes hypersensitivity in pain processing in the absence of nerve injury. This abnormality was associated with changes in the density of small fibers and ultrastructural changes in Remak bundles. A decrease in IENFD was observed, consistent with heightened sensitivity to pain. Furthermore, deletion of grin1 in SCs regulated the "pain-associated" DRG transcriptome, suggesting regulation of sensory neuron gene expression. GluN1- mice may represent a novel model system for studying SFN, fibromyalgia, and other poorly understood conditions in which chronic unremitting pain is experienced by patients.

Although a number of laboratories have reported that SCs express NMDA-Rs (Evans et al., 1991; Fink et al., 1999; Campana et al., 2017), the function of the NMDA-R in SCs remains unclear. We previously showed that cultured SCs respond to glutamate, which activates cell signaling and promotes SC migration (Campana et al., 2017). A second important 

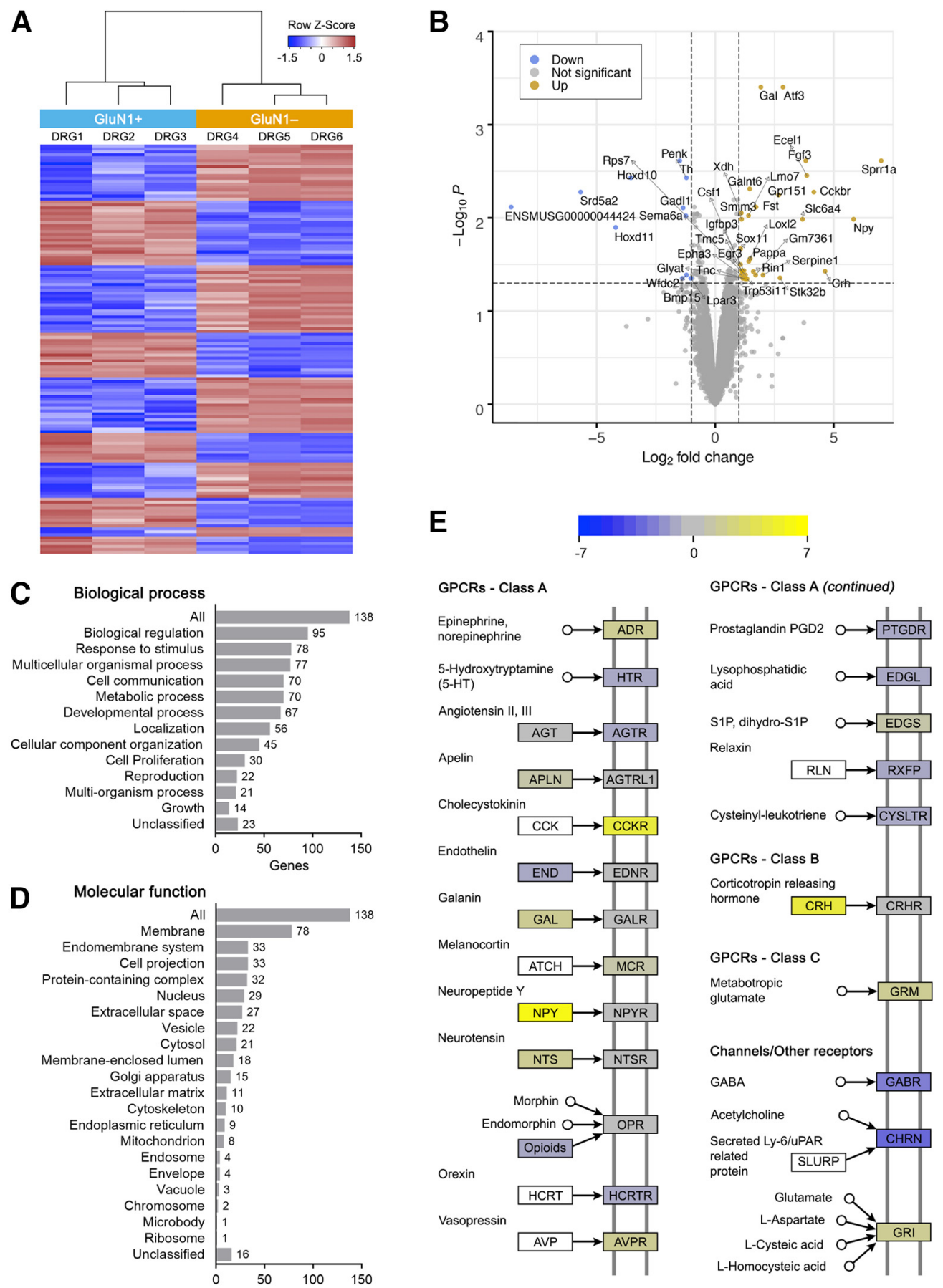

Figure 8. Differentially regulated genes in DRGs of GluN1+ and GluN1- mice. A, Hierarchical clustering and heat map analysis of differentially expressed genes (138 genes; adjusted $p$ $<0.05$ ). The scaled expression value (row $Z$ score) is shown in a blue-red color scheme with red indicating higher expression and blue indicating lower expression. $\boldsymbol{B}$, Volcano plot showing large fold changes that are also statistically significant. These may be the most biologically significant genes. The dashed line shows where $p=0.05$, with points above having $p<0.05$ and points below having $p>0.05$. The gray points have a fold change $<2(\log 2=1) . C, D$, Gene ontology pathways that are enriched in differentially expressed genes. The number of genes enriched in $(\boldsymbol{C})$ biological processes or $(\boldsymbol{D})$ molecular functions are indicated. $\boldsymbol{E}$, KEGG pathway analysis demonstrating molecular interactions in the neuroactive ligand receptor network. The pathway was significantly regulated $(p<0.05)$. Yellow boxes are upregulated genes and blue boxes are down regulated genes. All data compare mice that are three months old.

function of the NMDA-R is to function as an essential component of a receptor system which, together with low-density lipoprotein receptor-related protein 1 (LRP1), activates cell signaling and cell migration in response to protein ligands in SCs (Mantuano et al., 2015). When the gene encoding LRP1 was conditionally deleted in SCs in mice (scLRP1- mice), using the same P0 promoter applied in the current study, neuropathic pain was exacerbated following partial nerve ligation (Orita et al., 2013). Abnormalities were identified in Remak bundles in scLRP1- mice and, although we did not complete comprehensive DRG transcriptome profiling in scLRP1- mice, a number of genes were regulated, which also were regulated in GluN1- mice, including ATF3 and sprrla (Poplawski et al., 2018). Thus, there is overlap in the phenotypes observed when the genes encoding either the NMDA-R GluN1 subunit or LRP1 are deleted in SCs. The GluN1- phenotype appears more severe in its effects on small fibers and pain processing. 
In adult GluN1- mice, changes in the density of $\mathrm{A} \delta$ and $\mathrm{A} \beta$ myelinated axons were detected by TEM without evidence for structural impairment of myelin. In addition, the density of Remak bundles was increased by greater than twofold. Overall, this change in proportion of fiber types was consistent with our observation that the density of SCs was increased in GluN1mice, as determined by both TEM and IHC for Sox10-positive nuclei. To understand these changes, we studied P5 and P15 nerves from GluN1- mice by TEM. P5 nerves were most remarkable for an increase in the density of not-myelinated sorted axons, whereas, at P15, the main feature was an increase in the abundance of clusters of non-myelinated axons apparently in association with a single SC. We viewed these latter structures as immature Remak bundles, as they contained both unsorted axons and axons individualized by SC basal lamina. Collectively, our TEM developmental studies are consistent with results in adult nerves. Although not a commonly observed developmental feature, an increase in the abundance of not-myelinated sorted axons at P5 has been observed before (Ommer et al., 2019), yet this abnormality evolved into a defect in myelinated axon populations. Our results suggest that not-myelinated sorted axons also may coalesce, with the extra SCs undergoing apoptosis, to form immature Remak bundles. Alternatively, a greater number of not-myelinated sorted axons observed in the GluN1- nerves contributed to the greater number of $\mathrm{A} \delta$ fibers observed. This model is consistent with SC elongation, apoptosis and proliferation being intimately connected to radial sorting (Webster et al., 1973).

We considered the possibility that changes in PNS ultrastructure in GluN1- mice may be related to PI3K and ERK1/2 signaling. Activation of PI3K and ERK1/2 is essential in early SC differentiation (Maurel and Salzer, 2000; Newbern et al., 2011) and our studies performed with cultured SCs and using in vivo model systems indicate that the NMDA-R/LRP1 system may be a major determinant of the basal level of activation of these cellsignaling factors in SCs (Campana et al., 2006, 2017). Axon segregation and SC elongation are $\mathrm{PI} 3 \mathrm{~K}$ dependent (Maurel and Salzer, 2000). Thus, SCs with a lower level of PI3K activation may ensheath decreased lengths of axons, allowing for an increase in the number of SCs that associate with each axon, independently of one another, throughout the length of the sciatic nerve. In the absence of the NMDA-R, other receptor tyrosine kinases still activate PI3K and ERK1/2 pathways in SCs and are important for survival and myelination (Stewart et al., 1996; Campana et al., 1999; Taveggia et al., 2005).

Our results suggested that late radial sorting defects that impact Remak bundle structure did not occur in GluN1- nerves because an increase in the frequency of large axons in bundles was not observed. The ensheathment abnormalities identified in Remak bundle SCs in adult GluN1- mice are likely because of postradial sorting changes in SC differentiation as defined by Feltri et al. (2016). These aberrant axon ensheathments were prevalent, and resulted in highly variable spacing of neighboring axons. This is significant because when C-fibers come into contact, they provide a mechanism for impulse conduction through the nerve membrane in either direction and spontaneous ephaptic transmission (Sadjadpour, 1975; Ueda, 2008). When the distance between axons is abnormally large, nerve firing also may become aberrant. Changes in Remak bundle ultrastructure and pain were observed previously in mice with genetic deletion of LRP1 (Orita et al., 2013) or the GABA receptor (Faroni et al., 2014) in SCs.

Functional NMDA-Rs are expressed by peripheral glia in addition to SCs, including DRG satellite cells (Castillo et al., 2013). Our comprehensive analysis of DRG mRNA and protein showed that GluN1 levels were unchanged in GluN1- mice. However, DRGs contain multiple cell types including satellite 
Table 1. Top 15 most significantly regulated pain genes in GluN1 DRGs

\begin{tabular}{|c|c|c|c|c|c|c|c|c|c|}
\hline Symbol & $\begin{array}{l}\text { ENSEMBL } \\
\text { (ENSMUSG000000-) }\end{array}$ & ENTREZ ID & LogFC & $\begin{array}{l}\text { Glun1+ } \\
\text { average }\end{array}$ & $\begin{array}{l}\text { GluN1- } \\
\text { average }\end{array}$ & $\begin{array}{l}\text { Average } \\
\text { expression }\end{array}$ & $\begin{array}{l}\text { Adjusted } \\
p \text { value }\end{array}$ & Association with pain & References \\
\hline Gal & 24907 & 14419 & 1.9250 & 3.6055 & 5.5292 & 4.5673 & 0.00039 & $\begin{array}{l}\text { Functions as a predictive and prognostic } \\
\text { gene of neuropathic pain }\end{array}$ & \\
\hline Sprr1a & 50359 & 20753 & 6.9990 & -1.2523 & 5.7724 & 2.2600 & 0.00243 & $\begin{array}{l}\text { Upregulated in DRGs 5-d spared nerve } \\
\text { injury; a neuropathic pain model }\end{array}$ & $\begin{array}{l}\text { Tang et al. } \\
\text { (2020) }\end{array}$ \\
\hline Cckbr & 30898 & 12426 & 4.1617 & -1.5512 & 2.6217 & 0.5352 & 0.00527 & $\begin{array}{l}\text { Activation of Cckbr inhibits opioid } \\
\text { analgesia }\end{array}$ & $\begin{array}{l}\text { Yang et al. } \\
\text { (2018) }\end{array}$ \\
\hline Gpr151 & 42816 & 240239 & 2.6794 & 0.4850 & 3.1804 & 1.8327 & 0.00567 & $\begin{array}{l}\text { Facilitates pathogenesis of neuropathic } \\
\text { pain via ERK } 1 / 2 \text { signaling }\end{array}$ & $\begin{array}{l}\text { Jiang et al. } \\
\text { (2018) }\end{array}$ \\
\hline Fxyd2 & 59412 & 11936 & -0.9510 & 8.6866 & 7.7362 & 8.2114 & 0.00921 & $\begin{array}{l}\text { Underlies persistent hypersensitivity to } \\
\text { pain induced by inflammation }\end{array}$ & $\begin{array}{l}\text { Wang et al. } \\
\text { (2015) }\end{array}$ \\
\hline NPY & 29819 & 109648 & 5.8372 & -2.6726 & 3.1761 & 0.2518 & 0.01034 & $\begin{array}{l}\text { High protein-protein interaction with ATF3; } \\
\text { prognostic and therapeutic target for } \\
\text { neuropathic pain }\end{array}$ & $\begin{array}{l}\text { Tang et al. } \\
\text { (2020) }\end{array}$ \\
\hline $\begin{array}{l}\text { SIc17a8 } \\
\quad \text { (VGLUT3) }\end{array}$ & 19935 & 216227 & -0.9671 & 4.5242 & 3.5543 & 4.0392 & 0.01034 & $\begin{array}{l}\text { Injury induced mechanical hypersensitivity } \\
\text { by low threshold mechanoreceptors }\end{array}$ & $\begin{array}{l}\text { Seal et al. } \\
(2009)\end{array}$ \\
\hline Sox11 & 63632 & 20666 & 1.0725 & 1.5369 & 2.6027 & 2.0698 & 0.02142 & $\begin{array}{l}\text { Injury induced transcription factor that } \\
\text { upregulates BDNF }\end{array}$ & $\begin{array}{l}\text { Salerno et al. } \\
\text { (2012) }\end{array}$ \\
\hline Scn3b & 49281 & 235281 & -0.5600 & 6.9464 & 6.3862 & 6.6663 & 0.02307 & Control neuronal excitability & $\begin{array}{l}\text { Namadurai et } \\
\text { al. (2015) }\end{array}$ \\
\hline Ttyh2 & 34714 & 117160 & 0.6934 & 3.5562 & 4.2489 & 3.9026 & 0.02729 & $\begin{array}{l}\text { Chloride anion channel transport/BDNF; } \\
\text { sensitive to calcium }\end{array}$ & $\begin{array}{l}\text { Boudes et al. } \\
\text { (2009) }\end{array}$ \\
\hline
\end{tabular}

Table includes gene symbols, ENSEMBL numbers (last five digits), entrez ID, LogFC, average expression levels for GluN1+ and GluN1- mice, adjusted $p$ values, the association of the gene with pain processing, and references. All data were collected from DRGs ( $n=3 /$ genotype) comparing differential expression in GluN1+ and GluN1- mice.
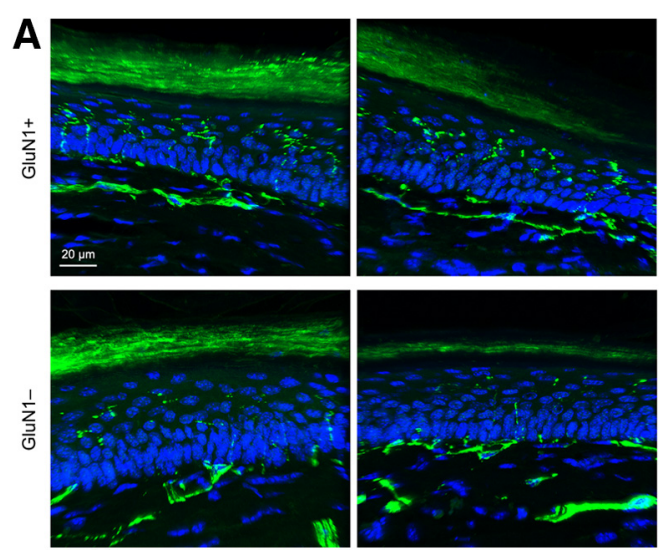

\section{B}

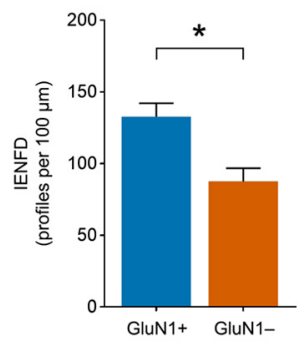

Figure 10. IENFD is decreased in GluN1- mice. $\boldsymbol{A}$, Images of hind paw skin biopsies immunostained for the pan-axonal marker, PGP9.5 (green) in uninjured GluN1 + (upper panel) and GluN1- (lower panel) mice. Nuclei are stained with DAPI (scale bar: $20 \mu \mathrm{m}) . B$, Quantification of the number of IENFD profiles (100 $\mu \mathrm{m}$ in diameter) in GluN1+ $(n=6)$ and GluN1$(n=4)$ skin biopsies (mean $\pm \mathrm{SEM}, t_{(8)}=3.285 * p=0.0111$, two-tailed unpaired $t$ test). Age matched, four- to sevenmonth-old, mice from both genotypes were compared.

cells and our analysis of whole tissue may have missed modest changes in a single cell type. Satellite cells do not express P0 (Jessen and Mirsky, 2005); however, because they are derived from the neural crest, we cannot completely rule out some level of P0-Cre activity in these cells. Importantly, activated satellite cells can induce nociceptor sensitization (Ferrari et al., 2014). Determining whether satellite cells contribute to the observed changes in pain processing in GluN1- mice is an important future goal.

grin1 deletion in SCs was associated with a substantial change in the transcriptome of DRGs in adult mice in the absence of injury. The GluN1- DRG transcriptome demonstrated many similarities with the transcriptome of mice experiencing neuropathic pain (Yang et al., 2018; Sun et al., 2020; Tang et al., 2020). Amongst the pain-related genes upregulated in the DRGs of GluN1mice, npy and atf 3 have been reported to be biomarkers of neuropathic pain when collectively upregulated. npy contributes to the pathogenesis of pain (Son et al., 2007) and ATF3 is a biomarker for neuronal activation and regeneration (Seijffers et al., 2007; Inoue et al., 2018). Cckbr encodes a G-protein coupled receptor, which is a pain therapeutic target (Bernstein et al., 1998) since antagonizing Cckbr minimizes opioid use in patients with severe burn injury (Yin et al., 2016). 
$f g f 3$ is upregulated in a subgroup of patients with paraneoplastic sensory neuron neuropathy (Antoine et al., 2015). SLC6A4 encodes the serotonin transporter and is expressed at increased levels in neuropathic pain, idiopathic trigeminal neuralgia and migraine (Cui et al., 2014; Kowalska et al., 2016; Calvo et al., 2019). SLC6A4 has been linked to the NMDA-R in the context of addiction (Karel et al., 2018) and fibromyalgia (Tour et al., 2017). Collectively, GluN1 - mice have a molecular expression signature that models SFN, fibromyalgia, and other chronic pain syndromes in which peripheral nerve injury is not obvious.

To further assess the abnormalities in GluN1- mice, we analyzed the IENFD in hind paws (Devigili et al., 2019). The IENFD was decreased in GluN1- mice. Decreases in IENFD are observed in painful HIV neuropathy, SFN caused by diabetes, and fibromyalgia (Periquet et al., 1999; Polydefkis et al., 2002; Pittenger et al., 2004; Evdokimov et al., 2019). It is assumed that decreased IENFD results from selective degeneration of small fibers near or in the skin. Because the NMDA-R is expressed by non-myelinating SCs (Campana et al., 2017) and terminal SCs (Woo et al., 2012) and both types of SCs are located in peripheral terminals, loss of terminal fibers may be related to SC abnormalities in GluN1- mice. Glutamate signaling is essential for proper development, maintenance, and differentiation of glial cells in the skin (Woo et al., 2012). These SCs have been shown to participate in sensation of mechanical stimuli (Abdo et al., 2019).

In summary, the NMDA-R is a major determinant of normal SC ultrastructure and function, particularly in non-myelinating SCs. grin1 deletion in SCs alters the DRG transcriptome is associated with pain-related behaviors. Overall, these studies demonstrate an important relationship between SC physiology and neuropathic pain.

\section{References}

Abdo H, Calvo-Enrique L, Martinez Lopez J, Song J, Zhang MD, Usoskin D, El Manira E, Adameyko I, Hjerling-Leffler J, Ernfors P (2019) Specialized cutaneous Schwann cells initiate pain sensation. Science 365:695-699.

Antoine J, Boutahar N, Lassabliere F, Reynaud E, Ferraud K, Rogemond V, Paul S, Honnorat J, Camdessanche J (2015) Anti-fibroblast growth factor receptor 3 antibodies identify a subgroup of patients with sensory neuropathy. J Neurol Neurosurg Psychiatry 86:1347-1355.

Asbury AK (1970) The histogenesis of phagocytes during Wallerian degeneration: Radio-autographic observations. Proceedings of the VIth International Congress of Neuropathology, pp 666-82. Paris: Masson \& Cie.

Benjamini Y, Hochberg Y (1995) Controlling the false discovery rate: a practical and powerful approach to multiple testing. J R Stat Soc Series B Stat Methodol 57:289-300.

Bernstein Z, Yucht S, Battista E, Lema M, Spaulding M (1998) Proglumide as a morphine adjunct in cancer pain management. J Pain Symptom Manage 15:314-320.

Bolger A, Lohse M, Usadel B (2014) Trimmomatic: a flexible trimmer for Illumina sequence data. Bioinformatics 30:2114-2120.

Boudes M, Sar C, Menigoz A, Hilaire C, Péquignot M, Kozlenkov A, Marmorstein A, Carroll P, Valmier J, Scamps F (2009) Best1 is a gene regulated by nerve injury and required for $\mathrm{Ca}+$ activated CL- current expression in axotomize sensory neurons. J Neurosci 29:10063-10071.

Calvo M, Davies A, Hébert H, Weir G, Chesler E, Finnerup N, Levitt R, Smith B, Neely G, Costigan M, Bennett D (2019) The genetics of neuropathic pain from model organisms to clinical application. Neuron 104:637-653.

Campana W (2007) Schwann cells: activated peripheral glia and their role in neuropathic pain. Brain Behav Immun 21:522-527.

Campana WM, Darin SJ, O’Brien JS (1999) Phosphatidylinositol 3-kinase and Akt protein kinase mediate IGF-/- and prosaptide-induced survival in Schwann cells. J Neurosci Res 57:332-341.

Campana WM, Li XQ, Dragojlovic N, Janes J, Gaultier A, Gonias SL (2006) The low density lipoprotein receptor related protein is a pro-survival receptor in Schwann cells: possible implications in peripheral nerve injury. J Neurosci 26:11197-11207.

Campana WM, Mantuano E, Azmoon P, Henry K, Banki M, Kim J, Pizzo D, Gonias S (2017) Ionotropic glutamate receptors activate cell signaling in response to glutamate in Schwann cells. FASEB J 31:1744-1755.

Castillo C, Norcini M, Martin Hernandez LA, Correa G, Blanck TJJ, RecioPinto E (2013) Satellite glia cells in dorsal root ganglia express functional NMDA receptors. Neuroscience 240:135-146.

Chaplan S, Bach F, Pogrel J, Chung J, Yaksh T (1994) Quantitative assessment of tactile allodynia in the rat paw. J Neurosci Methods 53:55-63.

Chen T, Kukley M (2020) Glutamate receptors and glutamatergic signalling in the peripheral nerves. Neural Regen Res 15:438-447.

Christensen P, Welch N, Brideau C, Stys P (2016) Functional ionotropic glutamate receptors on peripheral axons and myelin. Muscle Nerve 54:451459.

Clauw D (2015) What is the meaning of "small fiber neuropathy" in fibromyalgia? Pain 156:2115-2116.

Collison J (2018) CSF1 drives pain in arthritis. Nat Rev Rheumatol 14:562.

Cui W, Yu X, Zhang H (2014) The serotonin transporter gene polymorphism is associated with the susceptibility and the pain severity in idiopathic trigeminal neuralgia patients. J Headache Pain 15:42-47.

Dahlhamer J, Lucas J, Zelaya C, Nahin R, Mackey S, DeBar L, Kerns R, Von Korff M, Porter L, Helmick C (2018) Prevalence of chronic pain and high-impact chronic pain among adults - United States, 2016. MMWR Morb Mortal Wkly Rep 67:1001-1006.

Devigili G, Tugnoli V, Penza P, Camozzi F, Lombardi R, Melli G, Broglio L, Granieri E, Lauria G (2008) The diagnostic criteria for small fibre neuropathy: from symptoms to neuropathology. Brain 131:1912-1925.

Devigili G, Rinaldo S, Lombardi R, Cazzato D, Marchi M, Salvi E, Eleopra R, Lauria G (2019) Diagnostic criteria for small fibre neuropathy in clinical practice and research. Brain 142:3728-3736.

Dixon W (1980) Efficient analysis of experimental observations. Annu Rev Pharmacol Toxicol 20:441-462.

Dobin A, Davis C, Schlesinger F, Drenkow J, Zaleski C, Jha S, Batut P, Chaisson M, Gingeras T (2013) STAR: ultrafast universal RNA-seq aligner. Bioinformatics 29:15-21.

Evans P, Reale V, Merzon R, Villegas J (1991) N-methyl-D-aspartate (NMDAR) and non-NMDAR (metabotropic) receptors modulate the membrane potential of the Schwann cell of the squid giant nerve fibre. J Exp Biol 173:229-279.

Evdokimov D, Frank J, Klitsch A, Unterecker S, Warrings B, Serra J, Papagianni A, Saffer N, Meyer zu Altenschildesche C, Kampik D, Malik R, Sommer C, Úçeyler N (2019) Reduction of skin innervation is associated with a severe fibromyalgia phenotype. Ann Neurol 86:504-516.

Faroni A, Castelnovo L, Procacci P, Caffino L, Fumagalli F, Melfi S, Gambarotta G, Bettler B, Wrabetz L, Magnaghi V (2014) Deletion of GABA-B receptor in Schwann cells regulates Remak bundles and small nociceptive C-fibers. Glia 62:548-565.

Feltri ML, D'Antonio M, Previtali S, Fasolini M, Messing A, Wrabetz L (1999) P0-Cre-transgenic mice for inactivation of adhesion molecules in Schwann cells. Ann NY Acad Sci 883:116-123.

Feltri ML, Porta DG, Previtali SC, Nodari A, Migliavacca B, Cassetti A, Littlewood-Evans A, Reichardt LF, Messing A, Quattrini A, Mueller U, Wrabetz L (2002) Conditional disruption of beta 1 integrin in Schwann cells impedes interactions with axons. J Cell Biol 156:199-209.

Feltri ML, Poitelon Y, Previtali SC (2016) How Schwann cells sort axons: new concepts. Neuroscientist 22:252-265.

Ferrari LF, Lotufo CM, Araldi D, Rodrigues MA, Macedo LP, Ferreira SH, Parada CA (2014) Inflammatory sensitization of nociceptors depends on activation of NMDA receptors in DRG satellite cells. Proc Natl Acad Sci USA 111:18363-18368.

Fink T, Davey D, Ansselin A (1999) Glutaminergic and adrenergic receptors expressed on adult guinea pig Schwann cells in vitro. Can J Physiol Pharmacol 77:204-210.

Gasparotti R, Padua L, Briani C, Lauria G (2017) New technologies for the assessment of neuropathies. Nat Rev Neurol 13:203-216.

Gerevich Z, Borvendeg SJ, Schröder W, Frank H, Wirkner K, Nörenberg W, Fürst S, Gillen C, Illes P (2004) Inhibition of N-type voltage activated calcium channels in rat dorsal root ganglion neurons by $\mathrm{P} 2 \mathrm{Y}$ receptors is a possible mechanism of ADP-induced analgesia. J Neurosci 24:797-807.

Griffin J, Thompson W (2008) Biology and pathology of non-myelinating Schwann cells. Glia 56:1518-1531. 
Hargreaves K, Dubner R, Brown F, Flores C, Joris J (1988) A new and sensitive method for measuring thermal nociception in cutaneous hyperalgesia. Pain 32:77-88.

Harty B, Monk K (2017) Unwrapping the unappreciated: recent progress in Remak Schwann cell biology. Curr Opin Neurobiol 47:131-137.

Hunskaar S, Fasmer O, Hole K (1985) Formalin test in mice, a useful technique for evaluating mild analgesics. J Neurosci Methods 14:69-76.

Inoue M, Uchida Y, Edagawa M, Hirata M, Mitamura J, Miyamoto D, Taketani K, Sekine S, Kawauchi J, Kitajima S (2018) The stress response gene ATF3 is a direct target of the $\mathrm{Wnt} / \beta$-catenin pathway and inhibits the invasion and migration of HCT116 human colorectal cancer cells. PLoS One 13:e0194160.

Jessen KR, Mirsky R (1984) Nonmyelin-forming Schwann cells coexpress surface protein and intermediate filaments not found in myelin-forming cells: a study of Ran-2, A5E3 antigen and glial fibrillary acidic protein. J Neurocytol 13:923-934.

Jessen KR, Mirsky R (2005) The origin and development of glia cells in peripheral nerves. Nat Rev Neurosci 6:671-682.

Jiang BC, Zhang WW, Yang T, Guo CY, Cao DL, Zhang ZJ, Gao YJ (2018) Demethylation of G-protein-coupled receptor 151 promoter facilitates the binding of Krüppel-like factor 5 and enhances neuropathic pain after nerve injury in mice. J Neurosci 38:10535-10551.

Karel P, Calabrese F, Riva M, Brivio P, Van der Veen B, Reneman L, Verheij M, Homberg J (2018) d-Cycloserine enhanced extinction of cocaineinduced conditioned place preference is attenuated in serotonin transporter knockout rats. Addict Biol 23:120-129.

Kinkelin I, Bröcker E, Koltzenburg M, Carlton S (2000) Localization of ionotropic glutamate receptors in peripheral axons of human skin. Neurosci Lett 283:149-152.

Kowalska M, Prendecki M, Kozubski W, Lianeri M, Dorszewska J (2016) Molecular factors in migraine. Oncotarget 7:50708-50718.

Kuhlbrodt K, Herbarth B, Sock E, Hermans-Borgmeyer I, Wegner M (1998) Sox10, a novel transcriptional modulator in glial cells. J Neurosci 18:237250.

Lauria G, Bakkers M, Schmitz C, Lombardi R, Penza P, Devigili G, Smith A, Hsieh S, Mellgren S, Umapathi T, Ziegler D, Faber C, Merkies I (2010) Intraepidermal nerve fiber density at the distal leg: a worldwide normative reference study. J Periphe Nerv Syst 15:202-207.

Law C, Chen Y, Shi W, Smyth G (2014) voom: precision weights unlock linear model analysis tools for RNA-seq read counts. Genome Biol 15:R29.

Lee C, Lü W, Michel J, Goehring A, Du J, Song X, Gouaux E (2014) NMDA receptor structures reveal subunit arrangement and pore architecture. Nature 511:191-197.

Li B, Dewey C (2011) RSEM: accurate transcript quantification from RNASeq data with or without a reference genome. BMC Bioinformatics $12: 323$.

Luo W, Brouwer C (2013) Pathview: an R/bioconductor package for pathway-based data integration and visualization. Bioinformatics 29:18301831.

Mantuano E, Lam M, Shibayama M, Campana W, Gonias S (2015) The NMDA receptor functions independently and as an LRP1 co-receptor to promote Schwann cell survival and migration. J Cell Sci 128:3478-3488.

Maurel P, Salzer JL (2000) Axonal regulation of Schwann cell proliferation and survival and the initial events of myelination requires PI 3-kinase activity. J Neurosci 20:4635-4645.

Murinson B, Griffin J (2004) C-fiber structure varies with location in peripheral nerve. J Neuropathol Exp Neurol 63:246-254.

Namadurai S, Yereddi NR, Cusdin FS, Huang CLH, Chirgadze DY, Jackson AP (2015) A new look at sodium channel B subunits. Open Biol 5:140192.

Newbern JM, Li X, Shoemaker SE, Zhou J, Zhong J, Wu Y, Bonder D, Hollenback S, Coppola G, Geschwind DH, Landreth GE, Snider WD (2011) Specific functions for ERK/MAPK signaling during PNS development. Neuron 69:91-105.

Oaklander A (2016) What is the meaning of "small-fiber polyneuropathy" in fibromyalgia? An alternate answer. Pain 157:1366-1367.

Ommer A, Figlia G, Pereira JA, Datwyler AL, Gerber J, DeGeer J, Lalli G, Suter U (2019) Ral GTPases in Schwann cells promote radial axonal sorting in the peripheral nervous system. J Cell Biol 218:2350-2369.

Orita S, Henry K, Mantuano E, Yamauchi K, De Corato A, Ishikawa T, Feltri M, Wrabetz L, Gaultier A, Pollack M, Ellisman M, Takahashi K, Gonias S, Campana W (2013) Schwann cell LRP1 regulates Remak bundle ultrastructure and axonal interactions to prevent neuropathic pain. J Neurosci 33:5590-5602

Periquet M, Novak V, Collins M, Nagaraja H, Erdem S, Nash S, Freimer M, Sahenk Z, Kissel J, Mendell J (1999) Painful sensory neuropathy: prospective evaluation using skin biopsy. Neurology 53:1641-1641.

Pittenger G, Ray M, Burcus N, McNulty P, Basta B, Vinik A (2004) Intraepidermal nerve fibers are indicators of small-fiber neuropathy in both diabetic and non-diabetic patients. Diabetes Care 27:1974-1979.

Polydefkis M, Yiannoutsos C, Cohen B, Hollander H, Schifitto G, Clifford D, Simpson D, Katzenstein D, Shriver S, Hauer P, Brown A, Haidich A, Moo L, McArthur J (2002) Reduced intraepidermal nerve fiber density in HIV-associated sensory neuropathy. Neurology 58:115-119.

Poplawski G, Ishikawa T, Brifault C, Lee-Kubli C, Regestam R, Henry K, Shiga Y, Kwon H, Ohtori S, Gonias S, Campana W (2018) Schwann cells regulate sensory neuron gene expression before and after peripheral nerve injury. Glia 66:1577-1590.

Ritchie M, Phipson B, Wu D, Hu Y, Law C, Shi W, Smyth G (2015) limma powers differential expression analyses for RNA-sequencing and microarray studies. Nucleic Acids Res 43:e47.

Robinson M, Oshlack A (2010) A scaling normalization method for differential expression analysis of RNA-seq data. Genome Biol 11:R25.

Robinson M, McCarthy D, Smyth G (2010) edgeR: a bioconductor package for differential expression analysis of digital gene expression data. Bioinformatics 26:139-140.

Sadjadpour K (1975) Postfacial palsy phenomena: faulty nerve regeneration or ephaptic transmission? Brain Res 95:403-406.

Salerno KM, Jing X, Diges CM, Cornuet PK, Glorioso JC, Albers KM (2012) Sox11 modulates brain derived neurotrophic factor expression in an exon promoter specific manner. J Neurosci Res 90:1011-1019.

Schmid A, Bland J, Bhat M, Bennett D (2014) The relationship of nerve fibre pathology to sensory function in entrapment neuropathy. Brain 137: 3186-3199.

Seal RP, Wang X, Guan Y, Raja SN, Woodbury CJ, Basbaum AI, Edwards $\mathrm{RH}$ (2009) Injury induced mechanical hypersensitivity requires C-low threshold mechanoreceptors. Nature 462:651-655.

Seijffers R, Mills C, Woolf C (2007) ATF3 increases the intrinsic growth state of DRG neurons to enhance peripheral nerve regeneration. J Neurosci 27:7911-7920

Shillo P, Sloan G, Greig M, Hunt L, Selvarajah D, Elliott J, Gandhi R, Wilkinson I, Tesfaye S (2019) Painful and painless diabetic neuropathies: what is the difference? Curr Diab Rep 19:32.

Shy ME, Garbern JY, Kamholz J (2002) Hereditary motor and sensory neuropathies: a biological perspective. Lancet Neurol 1:110-118.

Son S, Lee K, Jeon S, Park E, Park K, Cho H (2007) Activation of transcription factor c-jun in dorsal root ganglia induces VIP and NPY upregulation and contributes to the pathogenesis of neuropathic pain. Exp Neurol 204:467-472.

Sopacua M, Hoeijmakers J, Merkies I, Lauria G, Waxman S, Faber C (2019) Small-fiber neuropathy: expanding the clinical pain universe. J Peripher Nerv Syst 24:19-33.

Stewart HJ, Bradke F, Tabernero A, Morrell D, Jessen KR, Mirsky R (1996) Regulation of rat Schwann cell Po expression and DNA synthesis by insulin like growth factors in vitro. Eur J Neurosci 8:553-564.

Subramanian A, Tamayo P, Mootha V, Mukherjee S, Ebert B, Gillette M, Paulovich A, Pomeroy S, Golub T, Lander E, Mesirov J (2005) Gene set enrichment analysis: a knowledge-based approach for interpreting genome-wide expression profiles. Proc Natl Acad Sci USA 102:15545-15550.

Sun W, Kou D, Yu Z, Yang S, Jiang C, Xiong D, Xiao L, Deng Q, Xie H, Hao Y (2020) A transcriptomic analysis of neuropathic pain in rat dorsal root ganglia following peripheral nerve injury. Neuromolecular Med 22:250-263.

Tang S, Jing H, Huang Z, Huang T, Lin S, Liao M, Zhou J (2020) Identification of key candidate genes in neuropathic pain by integrated bioinformatic analysis. J Cell Biochem 121:1635-1648.

Tarca A, Draghici S, Khatri P, Hassan S, Mittal P, Kim J, Kim C, Kusanovic J, Romero R (2009) A novel signaling pathway impact analysis. Bioinformatics 25:75-82.

Taveggia C, Zanazzi G, Petrylak A, Yano H, Rosenbluth J, Einheber S, Xu X, Esper RM, Loeb JA, Shrager P, Chao MV, Falls DL, Role L, Salzer JL (2005) Neuregulin-1 tyoe II determines the ensheathment fate of axons. Neuron 47:681-694.

Tour J, Löfgren M, Mannerkorpi K, Gerdle B, Larsson A, Palstam A, Bileviciute-Ljungar I, Bjersing J, Martin I, Ernberg M, Schalling M, Kosek 
E (2017) Gene-to-gene interactions regulate endogenous pain modulation in fibromyalgia patients and healthy controls-antagonistic effects between opioid and serotonin-related genes. Pain 158:1194-1203.

Ueda H (2008) Peripheral mechanisms of neuropathic pain - involvement of lysophosphatidic acid receptor-mediated demyelination. Mol Pain 4:11.

Wang F, Cai B, Li KC, Hu XY, Lu YJ, Wang Q, Bao L, Zhang X (2015) FXYD2, a $\gamma$ subunit of $\mathrm{Na}^{+}, \mathrm{K}^{+}$-ATPase, maintains persistent mechanical allodynia induced by inflammation. Cell Res 25:318-334.

Wang H, Wang X, Zhong S, Shen Z (2013) Novel method for culturing Schwann cells from adult mouse sciatic nerve in vitro. Mol Med Rep 7:449-453.

Webster HD, Martin JR, O'Connell MF (1973) The relationship between interphase Schwann cells and axons before myelination: a quantitative electron microscopic study. Dev Biol 32:401-416.

Wingett SW, Andrews S (2020) FastQ Screen: A tool for multi-genome mapping and quality control. F1000Res 7:1338.
Wong C, Gilkes D, Zhang H, Chen J, Wei H, Chaturvedi P, Fraley S, Wong C, Khoo U, Ng I, Wirtz D, Semenza G (2011) Hypoxia-inducible factor 1 is a master regulator of breast cancer metastatic niche formation. Proc Natl Acad Sci USA 108:16369-16374.

Woo S, Baba Y, Franco A, Lumpkin E, Owens D (2012) Excitatory glutamate is essential for development and maintenance of the piloneural mechanoreceptor. Development 139:740-748.

Yang J, He J, Lu J, Jie L (2018) Jun, Gal, Cd74, and C1qb as potential indicator for neuropathic pain. J Cell Biochem 119:4792-4798.

Yin K, Deuis J, Lewis R, Vetter I (2016) Transcriptomic and behavioural characterisation of a mouse model of burn pain identify the cholecystokinin 2 receptor as an analgesic target. Mol Pain 12: 174480691666536.

Zhang B, Kirov S, Snoddy J (2005) WebGestalt: an integrated system for exploring gene sets in various biological contexts. Nucleic Acids Res 33: W741-W748. 